\title{
Temporal dynamics of the developing lung transcriptome in three common inbred strains of laboratory mice reveals multiple stages of postnatal alveolar development
}

\author{
Kyle J Beauchemin ${ }^{1,2}$, Julie M Wells ${ }^{1}$, Alvin T Kho \\ Joel H Graber ${ }^{1}$, Carol J Bult ${ }^{\text {Corresp. } 1}$ \\ 1 The Jackson Laboratory, Bar Harbor, Maine, United States \\ 2 Graduate School of Biomedical Sciences and Engineering, The University of Maine, Orono, Maine, United States \\ 3 Computational Health Informatics Program, Boston Children's Hospital, Boston, Massachusetts, United States \\ 4 Department of Biomedical Informatics, Harvard Medical School, Boston, Massachusetts, United States \\ Corresponding Author: Carol J Bult \\ Email address: carol.bult@jax.org
}

To characterize temporal patterns of transcriptional activity during normal lung development, we generated genome wide gene expression data for 26 pre- and post-natal time points in three common inbred strains of laboratory mice (C57BL/6), A/J, and $\mathrm{C} 3 \mathrm{H} / \mathrm{HeJ}$ ). Using Principal Component Analysis and least squares regression modeling, we identified both strain-independent and strain-dependent patterns of gene expression. The 4683 genes contributing to the strain-independent expression patterns were used to define a murine Developing Lung Characteristic Subtranscriptome (mDLCS). Regression modeling of the Principal Components supported the four canonical stages of mammalian embryonic lung development (embryonic, pseudoglandular, canalicular, saccular) defined previously by morphology and histology. For postnatal alveolar development, the regression model was consistent with four stages of alveolarization characterized by episodic transcriptional activity of genes related to pulmonary vascularization. Genes expressed in a strain-dependent manner were enriched for annotations related to neurogenesis, extracellular matrix organization, and Wnt signaling. Finally, a comparison of mouse and human transcriptomics from pre-natal stages of lung development revealed conservation of pathways associated with cell cycle, axon guidance, immune function, and metabolism as well as organism-specific expression of genes associated with extracellular matrix organization and protein modification. The mouse lung development transcriptome data generated for this study serves as a unique reference set to identify genes and pathways essential for normal mammalian lung development and for investigations into the developmental origins of respiratory disease. The gene expression data are available from the Gene Expression Omnibus (GEO) archive (GSE74243). Temporal expression patterns of mouse genes can be investigated using a study specific web resource 
(http://lungdevelopment.jax.org). 


\section{Introduction}

2 Proper development of the mammalian respiratory system requires the spatiotemporal coordination of molecular interactions among more than 40 different cell types (Breeze \&

4 Wheeldon 1977) to form a complex, highly branched structure and associated vasculature for 5 facilitating gas-exchange. Although there are differences between mouse and human lung anatomy and cell type distribution (Braun et al. 2012; Irvin \& Bates 2003; Keli et al. 2010;

7 Wright et al. 2008), the basic morphological hallmarks of the developing lung are comparable

8 between mouse and human (Rackley \& Stripp 2012). These conserved features make the

9 laboratory mouse an invaluable model system for identifying and characterizing genes,

10 pathways, and networks that are fundamental to normal lung development and disease in humans

11 (Dutt \& Wong 2006; Moore et al. 2013; Rawlins \& Perl 2012; Wright et al. 2008).

13 The process of mammalian lung development is traditionally described as five stages defined by

14 histological features, cell type composition, and morphology: embryonic, pseudoglandular,

15 canalicular, saccular, and alveolar (Have-Opbroek 1991; Warburton et al. 2000) (Fig. 1). In

16 mice, lung development initiates during the embryonic stage (EMB) with the emergence of lung

17 buds from the ventral foregut endoderm and subsequent septation from the esophagus. Several growth factors and transcription factors including NK2 homeobox 1 (Nkx2.1), GATA binding

19 protein 6 (Gata6), GLI-Kruppel family members 2 and 3 (Gli2/3), Sonic hedgehog (Shh), and

20 Fibroblast growth factor $10(F g f 10)$ are key molecular drivers of this initiation phase (Lu et al.

21 2005; Millien et al. 2008; Warburton et al. 2005; Weaver et al. 2000). The pseudoglandular

22 stage (PSG) is characterized by stereo-specific branching morphogenesis of the lung bronchi and

23 the formation of pre-alveolate saccules (Herriges et al. 2012; Metzger et al. 2008). Branching

24 morphogenesis is an iterative process of bud growth, elongation, and subdivision of terminal

25 units, which ultimately generates the bronchial tree, complete with secretory gland, blood

26 vessels, and inter alveolar septa (Lu et al. 2004). Genes that underlie branching morphogenesis

27 include members of several well-known developmental signaling pathways (e.g, wingless-type

28 MMTV integration site family (WNT), FGF, and transforming growth factor beta (TGFb) as

29 well as homeobox-containing, zinc finger, forkhead box-containing, SRY-containing, and ETS 
30 domain containing genes (Herriges et al. 2012; Lu et al. 2004; Minoo et al. 1999). The

31 canalicular stage (CAN) follows the formation of the terminal bronchioles of the five lung

32 lobes. This stage is defined by expansion of the canaliculi, which form the pulmonary

33 parenchyma, and concurrent expansion of the surrounding capillary network. This

34 vascularization of the lungs is largely driven by interdependent vascular endothelial growth

35 factor (VEGF) signaling between the vascular endothelium and pulmonary epithelium

36 (Warburton et al. 2010). Dramatically increased vascularization and establishment of saccules

37 (primitive alveoli) within the canaliculi characterizes the start of the saccular stage (SAC)

38 during which immature terminal sacs form as primitive respiratory sites poised for gas exchange

39 following birth. Morphologically, expansion of the capillary bed continues during this stage,

40 along with pulmonary innervation and establishment of the lymphatic network (Schraufnagel

41 2010). The development of secondary septa to transform terminal sacs into mature alveolar ducts

42 and alveoli finally occurs post-birth during the alveolar stage (ALV). There is continuing debate

43 over the definition of the alveolar stage. Some groups have described postnatal maturation as an

44 extension of the saccular stage of development (Warburton et al. 2010) while others have

45 proposed two distinct phases of postnatal alveolarization (Mund et al. 2008; Schittny et al. 2008).

47 Several previous studies have reported on genome-wide gene expression profiling to characterize

48 transcriptional programs active during lung development in both mouse (Bonner et al. 2003; Kho

49 et al. 2009; Lu et al. 2004; Mariani et al. 2002; Xu et al. 2012) and human (Kho et al. 2010) (Fig.

50 1). In mouse, these studies have identified genes and networks involved in branching

51 morphogenesis (Lu et al. 2004), cell cycle/apoptosis (Bonner et al. 2003),

52 alveolarization/maturation (Kho et al. 2009; Xu et al. 2012) and extracellular matrix (ECM)

53 development (Mariani et al. 2002). Treutlein et al. (Treutlein et al. 2014) used single cell RNA-

54 Seq to characterize the lung epithelium lineage hierarchy in mouse, expanding our knowledge of

55 lung-specific epithelial cell types and the molecular markers that can be used to identify those

56 cell types. The LungMAP project (www.lungmap.net) is using "next generation" sequencing

57 technologies to profile gene expression in the laboratory mouse from whole lung tissue and from

58 populations of sorted cells between late canalicular and saccular stages through alveolarization.

59 In humans, the most comprehensive transcriptomic analysis of lung development identified a 
60 novel molecular substage of the pseudoglandular stage that is not readily apparent by histology

61 (Kho et al. 2010). Even with the discoveries of the genomic contributions to the developing lung

62 in mouse and human enabled by these previous transcriptional surveys, gaps remain in our

63 understanding of the temporal dynamics of gene expression during mammalian lung

64 development, how genetic variation can alter expression patterns in different strains of laboratory

65 mice, and the degree to which the core set of lung development genes in human compare to

66 mouse.

67

68 We report here a study of genome-wide gene expression during normal lung development and

69 maturation in three inbred laboratory strains of mice (A/J, C57BL/6J, and C3H/HeJ). Relative to

70 previous transcriptomics studies in the laboratory mouse, our study includes greater temporal

71 resolution of time points during pre- and post-natal stages of murine lung development (Fig. 1)

72 and serves as the most comprehensive genomic characterization of murine lung development to

73 date. The three mouse strains included in our study were selected based on known differences in

74 their normal lung physiology and respiratory disease susceptibility, including lung function

75 (Reinhard et al. 2002; Schulz et al. 2002; Soutiere et al. 2004), response to radiation-induced

76 lung damage (Jackson et al. 2011), susceptibility to lung cancer (Gariboldi et al. 2003; Gordon \&

77 Bosland 2009; Hoag 1963) susceptibility to pulmonary fibrosis (Haston et al. 1996; Lemay \&

78 Haston 2005; Walkin et al. 2013), airway responsiveness (De Sanctis \& Drazen 1997; Whitehead

79 et al. 2003), and airway remodeling (Shinagawa \& Kojima 2003). The patterns of differential

80 gene expression observed among these strains serves as the basis to identify developmental

81 genomic factors that may contribute to adult respiratory disease susceptibility. The developing

82 lung transcriptomics data described here are a unique resource for 1) identifying key

83 transcriptional programs required for normal murine lung development, 2) understanding the

84 genomic basis for strain specific differences in lung biology, 3) comparing genomics of lung

85 development in mouse and human, and 4) providing insights into the relationship of normal lung

86 development to respiratory disease processes (Desai \& Cardoso 2002; Gariboldi et al. 2003; Shi

87 et al. 2007; Yates \& Dean 2011). 


\section{Materials and Methods}

\section{$90 \quad$ Tissue and RNA}

91 Embryos and mice for this study were collected from timed pregnant mice for C57BL/6J (B6;

92 stock \# 000664), A/J (AJ; stock \# 000646), and C3H/HeJ (C3H; stock \# 000659) inbred lines

93 from The Jackson Laboratory. Whole lungs were surgically dissected at embryonic (E) days

94 E11.5, E12.5, E13.5, E14.5, E15.5, E16.5, E17.5, E18.5, E19.5 (A/J only) and postnatal (P) days 95 P0, P2, P3, P4, P5, P7, P9, P11, P12, P13, P14, P18, P21, P24, P30, and P56 (Fig. 1). Dissected 96 tissues were placed immediately in RNALater (Ambion) and stored at $-80^{\circ} \mathrm{C}$. Due to the 97 difficulty of manually dissecting lung buds at E9.5, whole embryos were harvested for RNA 98 extraction at this time point. For time points E11.5 and E12.5, tissues were pooled from multiple 99 embryos (four and three, respectively) to obtain sufficient RNA for array analysis. For all 100 subsequent time points, tissues from at least three animals were collected and analyzed 101 separately. As the A/J strain has an extra day of gestation relative to the other inbred strains used 102 in this study, embryos were collected at E19.5 only for this strain. Only male mice were used in 103 this study. The sex of every embryo and pup less than 21 days of age was determined by PCR of 104 105 106 DNA extracted from tail fragments using primers designed to amplify the male-specific Sry gene (MGI:98660) (Data S1). All animal work was performed in accordance with Jackson Laboratory animal case and use committee protocol 101011 (CJB).

Total RNA was extracted using mirVana RNA isolation kits (Ambion) following manufacturer's 109 directions. An additional DNase I (Promega) digestion step was added before organic extraction.

110 The quality of each RNA sample was assessed using RNA 6000 Nano LabChip assays and a 1112100 Bioanalyzer (Agilent Technologies, Palo Alto, CA). RNA purity (OD260/280 and OD 112 260/230 ratios) was assessed using a NanoDrop spectrophotometer (Thermo Fisher Scientific); 113 only samples with ratios above 2.0 were included in this study.

\section{Data processing}

115 Gene expression was assayed using the Affymetrix Mouse Gene 1.0 ST array platform 116 (Affymetrix). The .CEL files from the arrays were deposited in the Gene Expression Omnibus 
117 (GEO) archive at NCBI (Barrett et al. 2013) (Accession GSE74243). The array data were 118 processed using the DeSNPer pipeline developed at the Center for Genome Dynamics (CGD) at 119 The Jackson Laboratory (https://github.com/jaxcs/DeSNP). The DeSNPer algorithm removed 120 probes with single nucleotide polymorphisms (SNPs) (Yalcin et al. 2012) among the three strains 121 from further analysis to ensure that gene expression differences detected among the strains were not due to hybridization biases resulting from strain-specific sequence variation. Following probe removal, the data were log2-transformed, then probe-level hybridization intensities were quantile

124 normalized and median polished to generate summarized gene-level expression values (Irizarry 125 et al. 2003). A Z-score transformation was then applied, standardizing each gene to an average of zero and standard deviation of one across all samples. Finally, to focus data interpretation on the

127 dominant patterns of gene expression changes across the developmental time series, the dataset was filtered to retain the top $30 \%$ genes with the largest pre-Z-transform standard deviation (referred to as the "filtered dataset"; Data S2). The temporal expression patterns for all of the genes measured on the arrays can be visualized using the web interface implemented for this project (http://lungdevelopment.jax.org/).

\section{Principal Component Analysis (PCA)}

133 The filtered dataset described above (Data S2) was analyzed using Principal Component Analysis (PCA), a data transformation method to reduce the dimensionality of a dataset to those orthogonal components that account for the maximum variance in the data with the fewest number of observations. PCA was performed using $\mathrm{JMP}^{\circledR}$ v11.1.1 (SAS Institute) using the principal component toolset within the multivariate library. All default settings were used and no weighted bias was applied. PCA was first used to identify any systematic biases between samples, specifically among batches of arrays that were processed together (i.e. batch effects). This process identified a subset of 42 arrays that were strongly correlated with each other independent of strain or time point. The batches containing these arrays corresponded with changes in reagent chemistry used for array hybridization and were removed from further

144 expression variation between samples. This analysis generated two data matrices: gene loading 145 values (Data S3), which represent the correlation between each gene and the expression patterns 146 captured by each principal component (PC), and sample scores (Data S4), which reflect the 
147 relationship between each sample and each principal component. The gene loading values are 148 either positive or negative, with positive (negative) values reflecting correlation (anti-correlation) 149 between the gene expression and the sample score plot (Fig. S1). Characteristic gene sets for 150 each component were created using the most highly correlated genes (positively and negatively) 151 from each PC.

152 Regression analysis

153 Two standard least squares regression analyses were performed in $\mathrm{JMP}^{\circledR}$ (v11.1.1) to model the 154 strain and developmental time point effects associated with the gene expression patterns 155 identified by PCA. In the first analysis, the PCA score was modeled with independent additive 156 effects from developmental time point and mouse strain: $P_{i j}=a_{i}+b_{j}+e_{i j}$, where $P_{i j}$ is PCA score, $157 a_{i}$ is the effect of time point $i, b_{j}$ is the effect of strain $j$, and $e_{i j}$ is the residual for strain $j$ at time $i$. 158 There were not sufficient data to model a strain-by-time point interaction term. Multiple 159 hypothesis correction was implemented by controlling for FDR < 0.1 (Benjamini \& Hochberg 160 1995). The computed time point effects were plotted by component and used to identify contiguous bins of time points with similar PCA scores. These bins, in turn, were used to define gene expression-based stages of lung development. In cases of overlapping blocks between different block endpoints, a visual inspection was used to manually select the best grouping (e.g., postnatal time point 3 was grouped with P0 and P2, but could alternatively have been included with P4 and P5).

In the second analysis, PCA score was modeled as function of strain, stage, and the interaction of strain and stage using the stages identified in the first regression analysis: $P_{i j}=d_{i}+b_{j}+g_{i j}+e_{i j}$, where $P_{i j}$ is PCA score, $d_{i}$ is the effect of developmental stage $i, b_{j}$ is the effect of strain $j, g_{i j}$ is the interaction term between stage $i$ and strain $j$, and $e_{i j}$ is the residual for strain $j$ at time $i$. Effect significance was corrected for by multiple hypothesis testing at FDR $<0.1$, and pairwise

173 Kramer Honestly Significant Difference (HSD) test (Kramer 1956). The second regression 174 analysis was performed to estimate effects for each strain (presumed to be constant across all 175 time points), effects for each stage (presumed to be constant across all strains), and effects for 
176 each strain at each stage, allowing for the identification of stage-specific differences among 177 strains for each PCA component.

179 Genes from the filtered dataset (Data S2) were binned based upon their patterns of expression as 180 a function of stage and/or strain to identify strain-dependent differential expression. Standard 181 linear pairwise correlation analysis (Pearson correlation) was also used to quantify relationships 182 between strains from each PCA score (Table 1).

\section{Differential gene expression analysis: Significance of Microarrays (SAM)}

184 Differential gene expression between stages of development was determined using Significance 185 Analysis of Microarrays (Tusher et al. 2001) with a median FDR $=0$ using the TM4 package 186 (Saeed et al. 2003). Binning of individual time points was based on the developmental stages 187 defined by the regression analysis described above.

\section{Quantitative Real-Time PCR (qPCR) validation of strain-specific gene expression}

We used quantitative Real-Time PCR (qPCR) to validate strain-specific expression of selected genes. cDNA was generated from nine samples of total RNA originally used for microarray analysis, using RT $^{2}$ First Strand Kit (Qiagen) following manufacturer's directions. cDNA was generated from three biological replicates for each strain at postnatal day 13 (P13). This time point was chosen, in part, because the strain-specific expression differences of the genes selected for validation (see below) were evident at this time and there was sufficient quantities of the same high quality RNA used for the microarray analysis to use for qPCR. Gene expression was assayed using RT $^{2}$ SYBR Green ROX qPCR MasterMix Kit (Qiagen) following manufacturer's directions. Three genes with low variation in expression by time point or strain (Actb, Rpl10, Rpl13a) were used to normalize expression values of the target genes. A geometric mean of the

201 Following normalization, relative expression values were calculated for each target gene (Fggy,

202 Saa3, Wnt11, Wif1) within all biological groups. The genes for validation were selected because 203 of their relevance to fibrosis-related biological processes that are known to differ among inbred 
204 strains of mice (Walkin et al. 2013). The significance of differences between strains in relative 205 expression arbitrary units (A.U.) was assessed by Tukey Multiple testing corrected ANOVA 206 using Prism v7.0a (GraphPad Software). Primer sequences used for qPCR were as follows: Actb, 207 5'-GTGACGTTGACATCCGTAAAGA-3', 5'-GCCGGACTCATCGTACTCC-3'; Rpl10, 5'208 CGTGGTGTCCCTGATGCTAAG-3', 5'-GTTGGCACAAATACGGGCAG-3'; Rpl13a, 5'209 AGCCTACCAGAAAGTTTGCTTAC-3', 5'-GCTTCTTCTTCCGATAGTGCATC-3'; Fggy, 210 5'-CGGCTCTAGTGGACCAGAGA-3', 5'-ATGTGCATCAATCCCTTGAACA-3'; Saa3, 5'211 AGAGAGGCTGTTCAGAAGTTCA-3', 5'-AGCAGGTCGGAAGTGGTTG-3'; Wnt11, 5'212 ATGCGTCTACACAACAGTGAAG-3', 5'-GTAGCGGGTCTTGAGGTCAG-3'; Wif1, 5'213 CCTGCCGAAATGGAGGTAAA-3', 5'-GCTGGCTCCATACCTCTTATTG-3'.

\section{Annotation term enrichment analysis}

216 Annotation enrichment analysis was performed to guide the interpretation of gene sets associated 217 with specific developmental stages and for those contributing to individual principal components 218 (PCs). Probe set identifiers from the Affymetrix arrays were first mapped to mouse gene 219 identifiers using Mouse Genome Informatics (MGI) database Batch Query tool (Bult et al. 2010).

220 Sets of mouse gene symbols or gene accession identifiers were submitted for Gene Ontology 221 (Gene Ontology 2015) and Mammalian Phenotype Ontology (Smith \& Eppig 2012) term 222 enrichment analysis using VisuaL Annotation Display (VLAD) v1.5.1 (Richardson \& Bult 223 2015). Mouse genes that were converted to human homologs were also analyzed using the 224 Reactome Pathway Browser v52 (Croft et al. 2014) to identify enrichment of homologous 225 pathway annotations.

\section{Mouse and human gene homology}

227 Gene homology between mouse and human was used to compare transcriptional profile results 228 from this study to those from a previous study of human lung development (Kho et al. 2010). A 229 gene homology resource containing 10,266 genes was generated manually using homology 230 assertions from Panther (Mi et al. 2013) and Homologene (Sayers et al. 2012). If one gene 231 mapped to multiple homologs, each homolog was represented in the final set. For example, the 232 mouse alcohol dehydrogenase $1(A d h 1)$ gene is homologous to $A D H 1 A, A D H 1 B$, and $A D H 1 C$ in 
233 human; the carboxylesterase (CES) gene in human is homologous to Ces $1 d$, Cesle, and Ces $1 g$ in 234 mouse. Many-to-one homolog relationships were identified in 18 instances. Overlap between 235 lists of homologous genes was assessed with the GeneVenn tool (Pirooznia et al. 2007) using the 236 NCBI GeneID for the human gene as the primary gene accession identifier.

\section{$238 \quad$ Results}

239 Principal component analysis (PCA) was used to identify global patterns of variation in gene 240 expression across the lung development time series. Regression analyses were performed to 241 group time points into developmental stages and also to associate the global patterns identified

242 by PCA with specific effects of the experimental design, including strain and stage of 243 development.

244 Principal Component and regression analysis reveals nine stages of murine lung 245 development

246 The first three principal components (PCs) accounted for $66.2 \%$ of the variation among samples; 247 the first ten PCs accounted for $80.9 \%$ of the sample variation (Table 1). The patterns of variation 248 in gene expression represented by PCs 1-3 represent common patterns of expression that do not 249 very significantly between the three mouse strains (Fig. 2). In contrast, PCs 4-10 demonstrated 250 strain-specific patterns of expression variation (Fig. S2). Regression modeling supported the 251 PCA results (Table 1); no significance was detected among the strain or strain by stage effects 252 for PCs 1-3 whereas PC 4-10 all were found to have differences between one or more of the 253 strains for some of the developmental stages (Fig. 3). To identify possible temporal shifts in gene 254 expression patterns between strains, correlations across all strain by PC combinations were 255 performed. No significant correlations from this analysis were observed.

257 Regression analyses of the PCA results support the grouping of sampled time points into nine 258 stages of lung development (Fig. 4). The four prenatal stages, embryonic (EMB, E9.5-E12.5), 259 pseudoglandular (PSG, E13.5-E15.5), canalicular (CAN, E16.5-E17.5), and saccular (SAC, 
260 E18.5-E19.5) are concordant with those defined previously by histology and morphology. We 261 identified four molecularly distinct stages of alveolar development between P0-P18 (ALV1-4) 262 that are defined by the expression patterns and functional properties of differentially expressed 263 genes. Finally, the time points following alveolarization were grouped under the common 264 heading mature lung (MAT, P21-P56).

265 Strain-independent principal components 1-3 define a murine developing lung 266 characteristic subtranscriptome (mDLCS)

267 The first PC $(55.1 \%$ of the sample variation $)$ was significantly correlated $(\mathrm{P}<0.0001)$ with 268 developmental time point, capturing the patterns of gene expression across the entire 269 developmental timeline. Over $50 \%$ of the genes in our filtered dataset (Data S2) had relatively 270 high (positive) or low (negative) loading values on PC1. GO term enrichment analysis of genes 271 contributing to the prenatal signal $\left(\mathrm{PC}^{\mathrm{pos}}\right)$ revealed enrichment of genes associated with nucleic 272 acid metabolic process (GO:0090304) and RNA processing (GO:0006396). Genes previously 273 associated with lung cell differentiation were among the top 10\% of contributors to PC1 (Fig. 274 S6); a 3.2-fold enrichment (Fisher exact test; $\mathrm{P}<1.7 \times 10^{-3}$ ). Annotation enrichment analysis of 275 genes contributing to the postnatal signal $\left(\mathrm{PC}^{\mathrm{neg}}\right)$ identified enrichment of immune system 276 processes (GO:0002376), cellular communication (GO:0010646), and localization 277 (GO:0051179). Specifically, we observed postnatal induction of genes associated with RAS 278 protein superfamily (RAS), Ras-related protein 1 (Rap1), phosphatidylinositol 3-kinase/protein 279 kinase B (PI3K/Akt), and mitogen-activated protein kinase (MAPK) signaling as well as 280 chemokine signaling and phagocytosis/endocytosis, including seven toll-like receptors, four 281 lymphocyte antigens, six chemokine receptor/ligands, and eighteen interleukins (Table S1). 282 Many surfactants (4 of 4), mucins (2 of 4), and extracellular matrix genes (6 of 10 laminins; 7 of 21 collagens; 10 of 18 integrins) also contribute significantly to $\mathrm{PC} 1^{\text {neg }}$.

285 The pattern of sample variation captured by PC2 revealed major changes in gene expression 286 between the EMB/PSG and ALV3/ALV4 stages, depicted as shifts in PC2 sample coordinates 287 between stages (Fig. 2). The shift between EMB/PSG stages represents a molecular transition 288 from early embryonic organogenesis to prenatal epithelial/vascular development; genes that were 
289 significantly down regulated between these stages are primarily associated with embryonic 290 morphogenesis whereas up regulated genes are associated with cell migration and angiogenesis. 291 The shift at ALV3/ALV4 represents a transition from active cellular growth to homeostasis; 292 genes that were down regulated between these stages are associated with cell cycle whereas 293 genes that were up regulated are associated with metabolism (lipid, oxidation-reduction) and 294 immune response.

296 Shifts in gene expression captured by PC3 occur between the PSG/CAN, ALV1/ALV2, and 297 ALV4/MAT stages (Fig. 2). Down regulated genes between PSG/CAN are primarily associated 298 with cell cycle and up regulated genes are associated with cellular differentiation and 299 localization, suggesting that processes related to differentiation and morphogenesis dominate late 300 prenatal development. The shift between ALV1/ALV2 also represents a transition from metabolism/homeostasis to induction of cell cycle; down regulated genes between these stages are associated with lipid metabolism, chemical homeostasis, and localization while up regulated genes are highly enriched for cell cycle. All differentially expressed genes between molecular stages can be found in Supplemental Data S5.

The murine developing lung characteristic subtranscriptome. Because the sample scores for 307 PC1-3 were significantly correlated among the three inbred strains of mouse $(\mathrm{P}<0.0001)$ (Table 308 1), we used the genes contributing to these components to define a murine Developing Lung 309 Characteristic Subtranscriptome (mDLCS). The mDLCS represents a strain-independent core set 310 of genes associated with normal murine lung development. We defined the mDLCS using an 311 approach described previously for the human lung transcriptome (Kho et al. 2010) with some 312 modifications. Due to the bimodal distribution of gene loadings onto PC1 (Fig. 2) we included 3133468 genes with the most extreme positive (25\%) or negative (25\%) gene loadings on this 314 component. For PC2 and PC3, where gene loadings were more normally distributed, we included 3151396 genes with the highest positive (10\%) or lowest negative (10\%) loadings. The resulting set 316 of 4683 unique genes constitutes the mDLCS (Data S6). 
318 GO term enrichment analysis was used to identify the biological processes represented by the 319 genes contributing to the mDLCS. The results demonstrated significant enrichment for genes associated with general developmental processes (1371 genes) including, tube, cardiovascular, mesenchyme and epithelium development. Among this developmentally-enriched set were 84 genes specifically annotated as being involved in lung development including, early lung formation (Nkx2-1, Rdh10) (Kimura et al. 1996; Sandell et al. 2007), branching morphogenesis (Hoxa5, Fgfr1, Fgfr2) (Boucherat et al. 2013; Hokuto et al. 2003), pulmonary vascular development/epithelial-mesenchymal crosstalk (Wht5a, Shh, Fgf10, Fgf18) (Bellusci et al. 1997a; Bellusci et al. 1997b; Cornett et al. 2013; Usui et al. 2004), alveolarization/distal maturation (Hif3a, Errfil, Igfl) (Huang et al. 2013; Jin et al. 2009; Pais et al. 2013), and pulmonary inflammatory response (Igfbp4, Nedd4l, Apoe, Fgfr4) (Cantin et al. 2015; Kimura et al. 2011; Massaro \& Massaro 2008; Rezvani et al. 2013). A full report of the enrichment analysis results for the mDLCS is provided in supplemental data (Data S6).

To compare previously reported lung development genes in mouse with those captured by the mDLCS we compared the genes included in the mDLCS to lists of genes previously associated with lung development in the mouse (Data S7). We compiled a list of 657 genes from four previous transcriptomics studies (Bonner et al. 2003; Lu et al. 2004; Mariani et al. 2002; Xu et al. 2012). From this gene set, 161 genes were removed because they were not assayed by the Affymetrix Mouse 1.0ST array or did not pass variance filtering in the current study. Of the 496 unique genes that remained, the mDLCS included 406 genes (82\%). These genes included regulators of cellular adhesion $(C a v 1, C d h 1)$ and the neonatal immune response (Stat1, Egfr) (Xu et al. 2012), cell cycle regulation (Igf2, Mest, Peg3) (Finkielstain et al. 2009), and cellular metabolic processes associated with terminal differentiation (Elf3, Klf4) (Bonner et al. 2003). Among the 90 genes that were not included in the mDLCS, 59 were captured by one or more principal components (PC4-10) with strain-specific patterns in gene expression associated with lung development. 
346 We also compared the mDLCS gene list to all mouse genes currently annotated to the Gene

347 Ontology term "lung development" (GO:0030324) and to genes annotated with the Mammalian

348 Phenotype ontology term "respiratory system phenotype" (MP:0005388). We downloaded these

349 annotations from the MGI database (v6.01; 12/22/15) based on MGI's unified gene catalog

350 (genome assembly GRCm38) (Zhu et al. 2015). The resulting list included 209 genes annotated

351 to the GO term of lung development (GO:0030324) and its child terms and 1076 genes annotated

352 to the MP term "respiratory system phenotype" (MP:0005388) and its child terms; 134 genes

353 shared both "lung development" and "respiratory system phenotype" annotations. The gene list

354 from previous transcriptomic studies in mouse and the gene list created from GO and MP terms

355 overlapped by 32 genes. To ensure an accurate comparison, 9 and 27 genes that were not assayed

356 by the Affymetrix Mouse 1.0ST array were excluded from the GO and MP gene sets,

357 respectively. Genes with relevant GO and MP annotations that were not included in the mDLCS

358 because they failed the variance threshold were also removed from the comparison (83 and 496

359 genes, respectively). The final gene list for comparison to the mDLCS contained 117 lung

360 development genes and 553 respiratory system phenotype genes. The mDLCS contained 87 of

361117 "lung development" genes (74\%) and 381 of 553 "respiratory system phenotype" genes

362 (69\%); 57 of these genes captured by the mDLCS were annotated with both "lung development"

363 and "respiratory system phenotype". The lists genes with GO and MP annotations used for this

364 analysis are provided in Data S8.

The mDLCS contained 4596 genes that are not currently annotated with "lung development" and 4203 not annotated as "respiratory system phenotype." Some of these are well-known

368 development genes that have not been annotated specifically to lung development terms by GO curators. Others, however, represent novel lung development genes. For example, we discovered that four members of the dihydropyrimidinase-like 2 family (Dpysl2, Dpysl3, Dpysl4, Dpysl5)

371 are expressed during embryonic (EMB) and alveolar (ALV1-4) stages, suggesting a role for 372 these genes in pulmonary innervation during organogenesis and postnatal alveolarization. 373 Although these genes have not previously been reported as lung development genes, the 374 expression levels of the human homolog of Dpysl2 has been reported to be significantly 375 upregulated in the tumors of small cell lung cancer patients (Taniwaki et al. 2006). 
377 As reported above, PC 4-10 lacked significant correlation among the strains and regression 378 modeling revealed significant strain effects (Table 1). Of 20 calculated strain terms, 11 were 379 significant (FDR $<0.1$ ), including at least one term for each of PC 4-10. In contrast, only four 380 PCs $(5-6,9-10)$ had a significant interaction (strain*stage) effect for one or more developmental stages; of 180 calculated interaction terms, only 7 were judged significant (FDR $<0.1)$. Thus, the dominant strain-specific expression patterns captured by PC 4-10 are stage-independent, with only smaller stage-specific variations observed.

PCs 4-10 were evaluated for patterns of significant strain effects, specifically how the patterns differentiate each strain from the others. Although nineteen possible patterns of strain-dependent expression are possible with three strains, the results from regression modeling demonstrated that the following four classes account for nearly all strain-dependent effects (Fig. 3):

- $\mathrm{C} 3 \mathrm{H}$ different from indistinguishable pair AJ/B6 (PC4)

Regression modeling of gene expression as a function of strain, and subsequent Tukey HSD testing $(\mathrm{Q}<0.05)$, quantified the genes that significantly contributes to each class (Table 2). Gene expression associated with lung development is most dissimilar between $\mathrm{B} 6$ and $\mathrm{AJ}$ or $\mathrm{C} 3 \mathrm{H}$ mice; a 40/60 ratio of genes that are up versus down regulated in $\mathrm{B} 6$ relative to $\mathrm{AJ} / \mathrm{C} 3 \mathrm{H}$ was also observed. Differences between C3H vs AJ/B6 and AJ vs C3H/B6 exhibited 40/60 and 60/40 ratios of up versus down regulated genes, respectively. Differences between all strains were less common; only 57 strain-dependent genes (7.3\%) were differentially expressed between all three strains. Strain-dependent gene expression was validated by qPCR (Figure S11) in four target genes (Fggy, Saa3, Wnt11, Wifl). The qPCR results confirmed the trends observed in the array data despite the variation observed among biological replicates (Table S2). All strain effects 403 for Saa3 and Wifl were confirmed by qPCR; that is, Saa3 expression is greatest in C3H and 404 indistinguishable between $\mathrm{AJ}$ and $\mathrm{B} 6$ whereas Wifl expression is greatest in AJ and 
405 indistinguishable between $\mathrm{B} 6$ and $\mathrm{C} 3 \mathrm{H}$. The qPCR results for Fggy were consistent with the

406 trend of $\mathrm{AJ}<\mathrm{B} 6<\mathrm{C} 3 \mathrm{H}$; however, the expression differences were not statistically significant 407 between AJ and B6. Similarly Wnt11 expression was greatest in B6 but that B6 was not

408 statistically significant different from the AJ strain. These results suggest that the general trends 409 of strain-dependent expression captured by the arrays are robust but that expression of strain410 differences for individual genes should be validated by qPCR or single cell sequencing prior to 411 experimental follow up to investigate the biological significance of these differences.

C3H different from AJ and/or B6. Gene expression patterns for $\mathrm{C} 3 \mathrm{H}$ were significantly different 414 from AJ or B6 in nearly all strain-dependent components (PC 4-5, 8-10). Differences in the 415 expression of genes associated with cell migration, chemotaxis, and immune system function 416 contribute to this pattern. The induction of twelve genes (Amical, Cd24,Ccl3, Ccr3, Csf3r, 417 Cxcl13, Cxcr2, Nckapll, Ptafr, Retnlg, Saa3, Spp1) associated with immune system chemotaxis 418 was observed in $\mathrm{C} 3 \mathrm{H}$ (relative to $\mathrm{AJ}$ or $\mathrm{B} 6$ ) during late postnatal stages of alveolarization ALV3 419 and ALV4 (Fig. S7). Furthermore, 20 genes associated with chemotaxis (GO:0006935) follow a 420 similar pattern distinguishing $\mathrm{B} 6$ from $\mathrm{C} 3 \mathrm{H}$. These differences in chemotactic signaling may be 421 partly explained by strain-dependent differences in respiratory immune cell populations; 422 specifically $\mathrm{CD} 103^{+}$dendritic cells, natural killer cells and/or TCR $\gamma \delta^{+} \mathrm{T}$ lymphocytes 423 (Hackstein et al. 2012). Alternatively, increased expression of chemotactic factors during later 424 stages of alveolarization and vascular remodeling may suggest an extended period of lung 425 growth in $\mathrm{C} 3 \mathrm{H}$ mice, which are known to have significantly larger lungs (by volume) than either 426 B6 or AJ (Reinhard et al. 2002; Soutiere et al. 2004).

B6 different from AJ and/or C3H. Components distinguishing B6 from $\mathrm{C} 3 \mathrm{H}$ and AJ (PC6 and 429 PC7) have opposite strain effects yet highly similar temporal profiles (stage effects) suggesting 430 they capture four sets of genes (one positive set and one negative set per PC) that are modulated 431 in sync throughout lung development; two of these gene sets (PC6 ${ }^{\mathrm{pos}}$ and $\mathrm{PC}^{\text {neg }}$ ) are expressed 432 higher in $\mathrm{B} 6$ whereas the other two $\left(\mathrm{PC}^{\text {neg }}\right.$ and $\left.\mathrm{PC}^{\mathrm{pos}}\right)$ are expressed higher in $\mathrm{AJ}$ and $\mathrm{C} 3 \mathrm{H}$ (Fig. 433 3). Characteristic genes contributing to the $\mathrm{B} 6^{\text {high }}$ signal ( $\mathrm{PC}^{\mathrm{pos}}$ and $\mathrm{PC} 7^{\text {neg }}$ ) were enriched for 
434 cellular component ECM, and biological processes related to branching morphogenesis and 435 neurogenesis. Characteristic genes contributing to the $\mathrm{B}^{\text {low }}$ signal $\left(\mathrm{PC}^{\text {neg }}\right.$ and $\mathrm{PC}^{\mathrm{pos}}$ ) were 436 enriched for biological processes lung alveolus development, respiratory tube development, lung 437 cell differentiation, and neurogenesis. Regression modeling of genes involved in neurogenesis 438 revealed 58 significant genes that were differentially expressed between $\mathrm{B} 6$ and $\mathrm{C} 3 \mathrm{H}$ or $\mathrm{AJ}$; 439 eight of these genes (Fig. S8) also had significant stage*strain effects differentiating expression 440 in B6 from $\mathrm{C} 3 \mathrm{H}$ or AJ during the embryonic (EMB) stage of development (Isl1, Foxp1, Nefl, 441 Nefm, Kif5c, Epha4, Sema3d, Nr2f1). These results suggest that genes involved in branching 442 morphogenesis and ECM function of the developing lungs are expressed at higher levels in B6 443 mice than $\mathrm{C} 3 \mathrm{H}$ or $\mathrm{AJ}$ mice. Conversely, genes involved in alveolar development and cellular 444 differentiation are expressed at lower levels in $\mathrm{n}$ the developing lungs of B6 mice compared to $445 \mathrm{C} 3 \mathrm{H}$ or $\mathrm{AJ}$ mice.

AJ different from $\mathrm{B} 6$ and $\mathrm{C} 3 \mathrm{H}$. Gene expression patterns distinguishing $\mathrm{AJ}$ from $\mathrm{B} 6$ or $\mathrm{C} 3 \mathrm{H}$ were detected on PC8. Genes contributing to this pattern (Fig. S9) were associated with a broad range of biological functions including metabolism and cellular growth (Ggh, Pnpo, Igfbp3, Itln1, $T b c b$ ), response to hypoxia (Chchd2), and the heat-shock degradation pathway (Dnajc10). Several of these genes also play peripheral roles in neuronal growth and/or physiology, suggesting that $\mathrm{AJ}$ mice may exhibit differences in pulmonary innervation or function compared to $\mathrm{C} 3 \mathrm{H}$ or $\mathrm{B} 6$ mice.

455 Because the three mouse strains included in this study are known to exhibit differences in 456 susceptibility to induced lung fibrosis $(\mathrm{B} 6>\mathrm{AJ}>\mathrm{C} 3 \mathrm{H})$ we investigated the strain-dependent 457 expression levels of genes in the pro-fibrotic Wnt signaling pathway (Chilosi et al. 2003; 458 Douglas et al. 2006; Konigshoff et al. 2008). A key regulator of epithelial-mesenchymal 459 crosstalk (Wnt2b) exhibits increased expression in $\mathrm{B} 6$ mice relative to $\mathrm{AJ}$ or $\mathrm{C} 3 \mathrm{H}$ throughout 460 most of lung development. Further investigation of Wnt family genes identified increased 461 postnatal expression of Wnt5a, Wnt10b, and Wnt11 in $\mathrm{B} 6$ mice relative to $\mathrm{AJ} / \mathrm{C} 3 \mathrm{H}$ as well as 462 decreased expression of Wnt-inhibitory factor 1 (Wifl) in B6 compared to AJ/C3H (Fig. S10A). 
463 Regression analysis confirmed significant strain-differences $(\mathrm{P}<.0001)$ in the expression of each 464 of these Wnt-related genes as well frizzled receptors 3, 4, and 6 (Wnt2b, Wnt10b, Wnt11, Wifl, $465 F z d 3, F z d 4, F z d 6)$. The expression profiles of 12 other genes associated with pulmonary fibrosis 466 (MP:0006050) were not correlated between strains (Fig. S10B) as determined by regression 467 analysis. Our analysis identified several additional genes with both strain-specific expression 468 patterns and reported roles in pulmonary fibrosis or immune function, including Cysltr2 (B6 > $469 \mathrm{AJ}>\mathrm{C} 3 \mathrm{H})[$ [Beller 2004], Asah1/Asah2 $(\mathrm{B} 6>\mathrm{AJ}=\mathrm{C} 3 \mathrm{H})$ [Dhami 2010], Hck $(\mathrm{B} 6>\mathrm{C} 3 \mathrm{H}>\mathrm{AJ})$ 470 [Ernst 2002], Gas5 (B6 > AJ = C3H) [Song 2014], and Cpa3 and Mcpt4 (C3H = AJ > B6) [Paun 471 2012]. These results suggest a potential role for Wnt signaling in the strain-dependent 472 modulation of vascularization during alveolar development, as well as shed light on putative 473 signaling pathways and immune modulators involved in conferring strain-dependent resistance 474 susceptibility to pulmonary fibrosis.

\section{Comparative analysis of the mouse and human embryonic developing lung characteristic} 476 subtranscriptomes

477 To investigate the genomic elements of lung development that are conserved between human and 478 mouse we performed PCA on a reduced set of murine samples (E12.5-E16.5) that corresponded 479 to the time points assayed in a previously published human Developing Lung Characteristic 480 Subtranscriptome dataset containing 3,209 genes (Kho et al. 2010). We generated a prenatal 481 mDLCS using the union of rank-ordered genes from PC1-3 that resulted in a set of 3077 genes. 482 Most of the genes (2302) in the prenatal mDLCS overlapped the mDLCS that included all 26 483 developmental time points.

485 Homologous human genes could not be identified for 464 of the prenatal mDLCS genes and 486 homologous mouse genes could not be identified for 201 of the hDLCS genes, leaving 2634 487 genes in the prenatal mDLCS for comparison to the $2997 \mathrm{hDLCS}$ gene set. The genes from the 488 prenatal mDLCS genes for which no human homolog could be found included predicted genes, 489 microRNAs, long non-coding RNAs (lncRNAs), and species-specific immune-related proteins 490 (e.g., major histocompatibility complexes). There were 771 genes shared in common (RF=2.3, P $491<2.4 \times 10^{-134}$ ) between the two datasets following the conversion of the mouse genes to human 
492 homologs; 2226 genes were unique to the hDLCS and 1861 genes were unique to the prenatal 493 mDLCS (Fig. 5).

495 There are two primary reasons for the lack of overlap of specific genes between the mouse and 496 human subtranscriptomes. First is the difference in the genes represented on the two gene 497 expression Affymetrix array platforms (Mouse 1.0ST and the Human 133 Plus 2.0). Mouse 498 homologs for 68 genes included in the hDLCS were not assayed by the Mouse 1.0ST array. 499 Second, mouse homologs for 1216 of the genes in the hDLCS lacked variance in expression 500 during embryonic development and were removed at the variance-filtering step prior to PCA. 501 These genes therefore, were not included in the prenatal mouse DLCS.

Although the overlap of individual genes between the hDLCS and mDLCS was small, the 504 biological processes and pathways represented by the DLCS gene lists were similar. Both DLCS gene sets were enriched in genes involved in broad developmental processes associated with lung development including cell cycle, lung-specific metabolism, signal transduction, and a wide range of immune functions (Table 3).

509 The 2226 genes unique to the hDLCS set were significantly enriched for cell cycle and DNA 510 repair processes, which may reflect differences in tissue quality, harvesting, and/or processing 511 between studies. The 1861 genes represented only in the mDLCS were enriched for high-level

512 biological processes (cell cycle, DNA replication) as well as ECM organization, specifically non513 integrin membrane-ECM interactions (LAMA3/4, LAMB1, COLAA1/4A2, COL2A1), ECM

514 proteoglycans, degradation of the ECM, and integrin cell surface interactions. The set of genes 515 associated with enrichment of ECM organization includes alpha/beta integrins (ITGA6/8, 516 ITGB6), laminins (LAMA3/4, LAMB1), collagens (COL1A2, COL2A1, COLAA1/2, COL6A1/2/3, 517 COL14A1, COL26A1), adhesion molecules (ICAM1/2, JAM2/3, VCAM1), cathepsins (CTSB, 518 CTSS, CTSV), and metallopeptidases (ADAMTS5/9, MMP14/19). These results suggest that 
519

520

521

522

523

524

525

526

527

528

529

530

531

532

533

534

535

536

537

538

539

540

541

542

543

544

545

546

underlying differences in ECM remodeling and/or composition may exist between the mouse and human prenatal developing lung microenvironment.

The previous human lung transcriptome study by Kho et al. (Kho et al. 2010) revealed evidence of a novel pseudoglandular substage between the $13^{\text {th }}-17^{\text {th }}$ weeks of human lung development (corresponding to E15.5 in mouse). Our mouse embryonic transcriptome data did not recapitulate this finding. Although the plots of PC sample scores for PC1 and PC2 in the B6 mouse strain show some similarity to the plots for the human data, strain-dependent variance of the PCA sample scores and the variance in gene expression for the B6 E15.5 time points complicate the comparisons. Only three of the more than 50 genes reported to be differentially expressed between the early and late pseudoglandular (PSG) time points in humans are differentially expressed between E14.5 and E15.5 in mouse: Sulf1, Muc1, and Sftpc. The lack of concordance between the mouse and human data is likely related to the sampling of lung development time points in mouse. The PSG sub stage defined in humans lasts approximately 5 weeks whereas the comparable developmental time in mice occurs over several hours. To definitively address the presence of a novel pseudoglandular stage in mouse would require sampling lung development at a much finer temporal scale (hourly) than was performed for the current study (one sample per day). An alternative explanation to the lack of a PSG substage in our murine dataset may lie in the fact that only male mice were used in this study; recent work in humans has revealed genderbased differences in transcriptional modulation surrounding this substage (Kho et al. 2015).

\section{Discussion and Conclusion}

In this report we present the results of the most comprehensive characterization of gene expression during normal murine lung development to date. The dataset consists of gene expression measured at 26 time points from E9.5-P56 in three common inbred strains of mice.

Using a combination of Principal Component and least squares regression analysis we identified strain independent and strain dependent patterns of genome wide transcription during pre- and post-natal development. These analyses provide significant impact for both basic and 
547 translational research into mammalian lung development through the generation of a high-

548 resolution molecular framework of murine lung development, comparative genomic analyses of

549 human and mouse lung development, and the identification of putative pathways associated with

550 respiratory pathology.

551 Principal components 1-3 suggest that lung development utilizes superimposed periodic 552 patterns of transcriptional control

553 The plots of PC sample scores for the first three principal components across the sampled 554 developmental time points revealed distinct periodic patterns of gene expression during lung 555 development (Fig. 2) similar to those reported recently for developmental gene expression in the 556 nematode, C. elegans (Hendriks et al. 2014). The temporal expression pattern for PC1 divides 557 the developmental timeline in two segments: 1) embryonic, pseudoglandular, and canalicular 558 stages versus 2) saccular, alveolar, and mature stages. The global trend is partially reversed in the 559 second and third alveolar stages. The singular transition point from embryonic to post-natal 560 pattern that occurs on PC1 between the canalicular and saccular stages supports the previous 561 assertion that the saccular stage of lung development is a critical period of preparation for the 562 switch to breathing air in mice (Kho et al. 2009). PC2 captures a developmental pattern of gene 563 expression that has two major changes, occurring between EMB and PSG stages and then 564 reversing again between ALV3 and ALV4 stages. As previously observed in Kho et al. (Kho et 565 al. 2009), PC2 effectively distinguishes stages temporally nearer to birth (PSG, CAN, SAC, 566 ALV1, ALV2, and ALV3) from those more distant (EMB, ALV4, and MAT). Finally, PC3 567 captures a pattern with four distinct phases, with transitions found between PSG and CAN, SAC 568 and ALV1, and ALV4 and MAT stages of development. In effect, the PC3 expression profile 569 from early embryo to birth is repeated from birth to maturity. Somewhat strikingly, where PC2's 570 expression profile is inverted in mature lungs compared to late embryological development, 571 PC3's profile matches that of late development. The regulatory control and consequences of 572 these periodic patterns of increasing frequency are topics for future inquiry.

573 Alveolarization in mouse has four distinct transcriptional stages suggesting waves of 574 vascularization and innervation 
575 A regression analysis of the principal components identified nine distinct stages of lung

576 development represented by the gene expression data. Five of these stages were consistent with

577 previous definitions of lung development (embryonic, pseudoglandular, canalicular, saccular,

578 and maturation following alveolarization). In contrast to previous studies that proposed alveolar

579 development as an extension of the saccular stage (Bonner et al. 2003) or as two stages (Mund et

580 al. 2008; Schittny et al. 2008) our data suggest subdivision of postnatal alveolarization into four

581 distinct stages (Fig. 4).

583 Differential gene expression analysis between successive stages of development revealed two 584 distinct waves of angiogenesis during alveolarization (Fig. 6). Multiple angiogenic regulators, 585 including Vegfa, Adora2b, Adrb2, Lgals3, Tgfb1 and Ang, were significantly induced in the first 586 alveolar stage (ALV1), relative to the saccular stage (SAC), and again in the fourth alveolar 587 stage (ALV4) relative to the third (ALV3). Further support of the two-phase pattern of 588 angiogenesis is found in the stage-specific (ALV2/ALV3) induction of genes associated with 589 negative regulation of angiogenesis (Thbs2, Agt) and/or vascular stabilization (Angpt1, Angpt2,

590 Serpine1, Igfl). Seven of these vascular stabilization genes were also expressed in the mature 591 lung (MAT) suggesting that there are periods of angiogenic "rest" during postnatal maturation 592 and adult homeostasis (Fig. S3). A similar dual-phase pattern of induction (ALV1 and ALV4593 MAT) was detected among genes known to be involved in alveolarization and neurogenesis (Fig. 594 S4; Fig. S5), suggesting extensive genomic coordination between vascular, neurogenic, and 595 alveolar processes in the postnatal lung development.

\section{PCs 1-3 define a "Developing Lung Characteristic Subtranscriptome" in mouse}

597 We combined the genes from the principal components that had no significant strain dependent 598 effects into a murine Developing Lung Characteristic Subtranscriptome (mDLCS). The mDLCS 599 represents the core set of genes expressed in specific temporal patterns during lung development 600 in the mouse, independent of strain-specific genetic effects. When we compared our mDLCS to 601 lists of genes known previously to be involved in murine lung development we determined that 602 the majority of these genes were represented in the mDLCS. There were two primary factors that 603 excluded previous lung development genes from our mDLCS. First, some genes did not pass the 
604 threshold we used to exclude genes from the PCA/regression analysis that defined the mDLCS. 605 For example, 7/20 GO-annotated genes and 67/115 MP-annotated genes that were not included 606 in the mDLCS were near the threshold criterion and would have been included with only minor 607 changes in the threshold requirements. Second, some genes were not included because they 608 displayed strain specific expression patterns and therefore were captured in PC4-10 instead of 609 PC1-3.

\section{Strain specific gene expression during lung development}

611 The inclusion of multiple inbred strains of mice in our study gave us the opportunity to identify

612 strain-dependent patterns of gene expression. Regression modeling revealed the majority of these

613 patterns represent global differences between strains that are independent of developmental

614 stage. The four primary patterns of strain-dependent expression that we uncovered were largely

615 characterized by expression differences in genes associated with ECM composition, lung

616 development, neurogenesis, immune system chemotaxis and function, and profibrotic pathway

617 signaling. Differences in leukocytic composition between strains may explain the strain-

618 dependent differential expression of chemotactic factors; however further investigation is

619 necessary to shed light on putative strain-dependent differences in pulmonary ECM composition, 620 alveolar versus bronchiolar development, and pulmonary innervation.

622 The expression profiles of several immune-related or profibrotic genes, including those that 623 influence inflammatory response, ECM remodeling through MMPs, and epithelial-mesenchymal 624 crosstalk, were among the genes showing strain differences and may help explain the known 625 differences in susceptibility for asthma and pulmonary fibrosis between B6 (susceptible) and AJ 626 (resistant) or $\mathrm{C} 3 \mathrm{H}$ (very resistant). Further investigation of the profibrotic Wnt signaling pathway 627 also identified gene expression differences between $\mathrm{B} 6, \mathrm{AJ}$, and $\mathrm{C} 3 \mathrm{H}$ mice that may explain 628 phenotypic differences in fibrotic susceptibility between strains. We observed increased 629 expression of mast-cell secretory factors (Cpa3, Mcpt4) in AJ and $\mathrm{C} 3 \mathrm{H}$ mice compared to $\mathrm{B} 6$ 630 immediately after birth, which may reflect differences in pulmonary inflammatory response 631 between strains and is consistent with experimental data showing elevated mast cell numbers and 632 exacerbated alveolitis in $\mathrm{AJ}$ and $\mathrm{C} 3 \mathrm{H}$ relative to $\mathrm{B} 6$ following radiation (Haston 2012). 


\section{Comparison of mouse and human embryonic lung development}

634 Our comparison of a murine embryonic DLCS to the previously published human embryonic

635 DLCS revealed only moderate overlap at the gene level. Among the genes we identified in common between the mDLCS and hDLCS were key cell differentiation factors (AGER, ABCA3,

637 GPRC5A, EGFL6), primary surfactant-/mucin-associated proteins (ADGRF5, CTSH, MUC1, $638 S R F P 1 / 2, S F T P A 1 / 2, S F T P B, S F T P C)$, or major structural components, including adhesive junction-associated proteins (CDH1, CADM1, MATR3, MLLT4, SCAPER) and tight junctionassociated claudins (CLDN5, CLDN18) (Table S2). The lack of substantial overlap of the DLCS gene lists at the level of individual genes may be due, in part, to the differences in the array platforms used in the two studies. Mouse lung expression was assayed using Affymetrix 1.0 ST

643 gene arrays where probesets are largely targeted to protein coding regions. In sharp contrast, the

644 human lung expression dataset used U133 Plus 2.0 arrays, which has probesets targeted 645 primarily to 3' untranslated regions (UTRs). Prior studies have frequently identified developmental and cell-specific transcript isoform variation specifically in the 3 '-UTR. The two

647 array designs will have different sensitivity to such variations, potentially resulting in very 648 different measurements, even with common transcript expression profiles, and subsequently 649 changing the identification of genes with enough variation for inclusion into downstream 650 analysis.

652 In contrast to the modest overlap of individual genes, the enriched annotations associated with 653 the genes in the mDLCS and hDLCS revealed many shared functional properties. Both 654 subtranscriptomes were enriched in genes involved in axon guidance, specifically through 655 L1CAM/NCAM interactions and signaling through semaphorins/Robo, suggesting pulmonary 656 neurogenesis events during prenatal development of the lung are highly conserved between 657 mouse and human. Several signaling transduction pathways were also enriched among conserved 658 elements of the mDLCS and hDLCS, including signaling through insulin receptors, protein 659 kinases, receptor tyrosine kinases, Wnt, and Rho GTPases. Developmentally associated growth 660 factor mediated signaling was also conserved including epidermal growth factor, fibroblast 661 growth factor receptor, platelet-derived growth factor, nerve growth factor, and stem cell factor. 
662 Both hDLCS and prenatal mDLCS gene sets were also enriched in general immune system 663 cytokine signaling, including interferon- and interleukin-signaling, as well as adaptive immune 664 system, including TCR signaling, MHC-II antigen presentation, and PD-1 signaling. This was 665 surprising since both subtranscriptomes are based entirely on pre-birth development time points 666 and suggests an unexpected role for adaptive immune system elements in prenatal lung development. Notable differences in annotation enrichment results between the mouse and

668 human subtranscriptomes were also detected. For example the mouse embryonic DLCS gene set 669 was enriched for genes involved in ECM organization whereas the human lung DLCS (but not murine) showed enrichment of genes involved in protein biosynthesis and protein modification.

672 The data reported here expand the current knowledge of genome wide temporal changes in gene 673 expression during the complex process of murine lung development, revealing novel stages of 674 postnatal alveolar development. The data generated for this study complement existing 675 transcriptomics data sets for murine lung development such as those that are available from the 676 LungMAP resource (http://www.lungmap.net/). The normal mouse lung gene expression time 677 course data available from LungMAP includes only two embryonic and two post-natal time 678 points for a single strain (C57BL/6). Our data support a much finer-grained assessment of the 679 temporal dynamics of gene expression across lung development and the ability to identify 680 possible strain-specific differences in expression. In contrast to our study, the LungMAP 681 resource includes some data for cell-specific expression (from sorted endothelial cell, myeloid 682 cell, and type II pneumocytes) at different development time points. These cell-specific 683 expression data can be integrated with our data to develop hypotheses about which cell types 684 may be contributing to the tissue level gene expression patterns observed in our data. Although a 685 full treatment of combining the data set reported here with LungMAP data is beyond the scope of 686 this report, the expression data for the angiogenin (Ang) gene serves as an example of the 687 complementary nature of these data resources. The general pattern of increased expression of 688 Ang over development is observed in both data resources (see www.lungmap.net and 689 www.lungdevelopment.jax.org). However our data reveal that the relative level of expression of 690 Ang is much higher in $\mathrm{C} 57 \mathrm{BL} / 6 \mathrm{~J}$ than in $\mathrm{A} / \mathrm{J}$ or $\mathrm{C} 3 \mathrm{H} / \mathrm{HeJ}$. This strain-specific difference is not 691 possible to detect in the existing LungMAP data. The cell-specific expression data from 
692 LungMAP suggests that type II pneumocytes are contributing most to the increased expression 693 of angiogenin between postnatal day 7 and day 28. This testable hypothesis would not be 694 possible to formulate using our data set alone.

695 Strain-specific differences in gene expression patterns were identified that serve as the basis for 696 future investigations into the genetic basis for well-known differences in adult lung physiology 697 and respiratory disease susceptibility among inbred mouse strains. Comparison of

698 developmental gene expression data between mouse and human highlighted conserved biological 699 processes as well as organismal differences that may be important for using the mouse as a 700 model for human respiratory biology and disease. The raw data files and processed data for this 701 study can be accessed at NCBI's Gene Expression Omnibus (GEO) data archive (GSE74243). 702 Expression patterns across stages (and time points) of lung development for all genes measured 703 by the Mouse Affymetrix Gene 1.0ST array can be queried, visualized, and downloaded at 704 http://lungdevelopment.jax.org/.

\section{Acknowledgements}

706 The authors are indebted to Dr. Marge Strobel and Ms. Rita Thibodeaux for their guidance and 707 assistance with establishing the mouse colonies used for this study. Ms. Karen Hammond and 708 Ms. Elsie Cough served as the Animal Care Technicians for the study. The gene expression 709 assays were performed Ms. Sonya Kamdar and Ms. Sandy Daigle of The Jackson Laboratory 710 Genome Technologies Scientific Services core. Dr. Nazira Bektassova assisted with the use of 711 the deSNPer software. Mr. Keith Sheppard (The Jackson Laboratory Computational Sciences 712 core) developed the database interface underlying the public gene expression visualization 713 website. Mr. Jesse Hammer (The Jackson Laboratory MultiMedia group) assisted with the 714 preparation of figures for this manuscript. This project was completed by KJB in partial 715 fulfillment of his graduate dissertation research in the Graduate School of Biomedical Sciences 716 and Engineering (GSBSE) at the University of Maine, Orono. 


\section{References}

718 Barrett T, Wilhite SE, Ledoux P, Evangelista C, Kim IF, Tomashevsky M, Marshall KA, Phillippy KH, Sherman PM, Holko M, Yefanov A, Lee H, Zhang N, Robertson CL, Serova N, Davis S, and Soboleva A. 2013. NCBI GEO: archive for functional genomics data sets--update. Nucleic Acids Res 41:D991-995. 10.1093/nar/gks1193

Bellusci S, Furuta Y, Rush MG, Henderson R, Winnier G, and Hogan BL. 1997a. Involvement of Sonic hedgehog (Shh) in mouse embryonic lung growth and morphogenesis. Development 124:53-63.

Bellusci S, Grindley J, Emoto H, Itoh N, and Hogan BL. 1997b. Fibroblast growth factor 10 (FGF10) and branching morphogenesis in the embryonic mouse lung. Development 124:4867-4878.

Benjamini Y, and Hochberg Y. 1995. Controlling the False Discovery Rate: A Practical and Powerful Approach to Multiple Testing. Journal of the Royal Statistical Society, Series B 57:289-300.

Bonner AE, Lemon WJ, and You M. 2003. Gene expression signatures identify novel regulatory pathways during murine lung development: implications for lung tumorigenesis. $J$ Med Genet 40:408-417.

Boucherat O, Montaron S, Berube-Simard FA, Aubin J, Philippidou P, Wellik DM, Dasen JS, and Jeannotte L. 2013. Partial functional redundancy between Hoxa5 and Hoxb5 paralog genes during lung morphogenesis. Am J Physiol Lung Cell Mol Physiol 304:L817-830. 10.1152/ajplung.00006.2013

Braun A, Ernst H, Schaudien D, Hoymann H, and Rittinghausen S. 2012. The Respiratory Tract: Elsevier.

Breeze RG, and Wheeldon EB. 1977. The cells of the pulmonary airways. American Review of Respiratory Disease 116:705-777.

Bult CJ, Kadin JA, Richardson JE, Blake JA, Eppig JT, and Mouse Genome Database G. 2010. The Mouse Genome Database: enhancements and updates. Nucleic Acids Res 38:D586592. 10.1093/nar/gkp880

Cantin AM, Hartl D, Konstan MW, and Chmiel JF. 2015. Inflammation in cystic fibrosis lung disease: Pathogenesis and therapy. J Cyst Fibros 14:419-430. 10.1016/j.jcf.2015.03.003

Chilosi M, Poletti V, Zamo A, Lestani M, Montagna L, Piccoli P, Pedron S, Bertaso M, Scarpa A, Murer B, Cancellieri A, Maestro R, Semenzato G, and Doglioni C. 2003. Aberrant Wnt/beta-catenin pathway activation in idiopathic pulmonary fibrosis. Am J Pathol 162:1495-1502.

Cornett B, Snowball J, Varisco BM, Lang R, Whitsett J, and Sinner D. 2013. Wntless is required for peripheral lung differentiation and pulmonary vascular development. Dev Biol 379:38-52. 10.1016/j.ydbio.2013.03.010

Croft D, Mundo AF, Haw R, Milacic M, Weiser J, Wu G, Caudy M, Garapati P, Gillespie M, Kamdar MR, Jassal B, Jupe S, Matthews L, May B, Palatnik S, Rothfels K, Shamovsky V, Song H, Williams M, Birney E, Hermjakob H, Stein L, and D'Eustachio P. 2014. The Reactome pathway knowledgebase. Nucleic Acids Res 42:D472-477. 10.1093/nar/gkt1102

De Sanctis GT, and Drazen JM. 1997. Genetics of airway responsiveness in the inbred mouse. Res Immunol 148:73-79; discussion 79-83.

Desai TJ, and Cardoso WV. 2002. Growth factors in lung development and disease: friends or foe? Respir Res 3:2. 
763

764

765

766

767

768

769

770

771

772

773

774

775

776

777

778

779

780

781

782

783

784

785

786

787

788

789

790

791

792

793

794

795

796

797

798

799

800

801

802

803

804

805

806

807

808

Douglas IS, Diaz del Valle F, Winn RA, and Voelkel NF. 2006. Beta-catenin in the fibroproliferative response to acute lung injury. Am J Respir Cell Mol Biol 34:274-285. 10.1165/rcmb.2005-0277OC

Dutt A, and Wong KK. 2006. Mouse models of lung cancer. Clin Cancer Res 12:4396s-4402s. 10.1158/1078-0432.CCR-06-0414

Finkielstain GP, Forcinito P, Lui JC, Barnes KM, Marino R, Makaroun S, Nguyen V, Lazarus JE, Nilsson O, and Baron J. 2009. An extensive genetic program occurring during postnatal growth in multiple tissues. Endocrinology 150:1791-1800. 10.1210/en.20080868

Gariboldi M, Spinola M, Milani S, Pignatiello C, Kadota K, Bono H, Hayashizaki Y, Dragani TA, and Okazaki Y. 2003. Gene expression profile of normal lungs predicts genetic predisposition to lung cancer in mice. Carcinogenesis 24:1819-1826. $10.1093 / \mathrm{carcin} /$ bgg 133

Gene Ontology C. 2015. Gene Ontology Consortium: going forward. Nucleic Acids Res 43:D1049-1056. 10.1093/nar/gku1179

Gordon T, and Bosland M. 2009. Strain-dependent differences in susceptibility to lung cancer in inbred mice exposed to mainstream cigarette smoke. Cancer Lett 275:213-220. 10.1016/j.canlet.2008.10.012

Hackstein H, Wachtendorf A, Kranz S, Lohmeyer J, Bein G, and Baal N. 2012. Heterogeneity of respiratory dendritic cell subsets and lymphocyte populations in inbred mouse strains. Respir Res 13:94. 10.1186/1465-9921-13-94

Haston CK. 2012. Mouse genetic approaches applied to the normal tissue radiation response. Front Oncol 2:94. 10.3389/fonc.2012.00094

Haston CK, Amos CI, King TM, and Travis EL. 1996. Inheritance of susceptibility to bleomycin-induced pulmonary fibrosis in the mouse. Cancer Res 56:2596-2601.

Have-Opbroek AA. 1991. Lung development in the mouse embryo. Exp Lung Res 17:111-130.

Hendriks GJ, Gaidatzis D, Aeschimann F, and Grosshans H. 2014. Extensive oscillatory gene expression during C. elegans larval development. Mol Cell 53:380-392. 10.1016/j.molcel.2013.12.013

Herriges JC, Yi L, Hines EA, Harvey JF, Xu G, Gray PA, Ma Q, and Sun X. 2012. Genomescale study of transcription factor expression in the branching mouse lung. Dev Dyn 241:1432-1453. 10.1002/dvdy.23823

Hoag WG. 1963. Spontaneous Cancer in Mice. Ann N Y Acad Sci 108:805-831.

Hokuto I, Perl AK, and Whitsett JA. 2003. Prenatal, but not postnatal, inhibition of fibroblast growth factor receptor signaling causes emphysema. J Biol Chem 278:415-421. 10.1074/jbc.M208328200

Huang Y, Kapere Ochieng J, Kempen MB, Munck AB, Swagemakers S, van Ijcken W, Grosveld F, Tibboel D, and Rottier RJ. 2013. Hypoxia inducible factor 3alpha plays a critical role in alveolarization and distal epithelial cell differentiation during mouse lung development. PLoS One 8:e57695. 10.1371/journal.pone.0057695

Irizarry RA, Bolstad BM, Collin F, Cope LM, Hobbs B, and Speed TP. 2003. Summaries of Affymetrix GeneChip probe level data. Nucleic Acids Res 31:e15.

Irvin CG, and Bates JH. 2003. Measuring the lung function in the mouse: the challenge of size. Respir Res 4:4.

Jackson IL, Vujaskovic Z, and Down JD. 2011. A further comparison of pathologies after thoracic irradiation among different mouse strains: finding the best preclinical model for 
809

810

811

812

813

814

815

816

817

818

819

820

821

822

823

824

825

826

827

828

829

830

831

832

833

834

835

836

837

838

839

840

841

842

843

844

845

846

847

848

849

850

851

852

853 evaluating therapies directed against radiation-induced lung damage. Radiat Res 175:510518. 10.1667/RR2421.1

Jin N, Cho SN, Raso MG, Wistuba I, Smith Y, Yang Y, Kurie JM, Yen R, Evans CM, Ludwig T, Jeong JW, and DeMayo FJ. 2009. Mig-6 is required for appropriate lung development and to ensure normal adult lung homeostasis. Development 136:3347-3356. 10.1242/dev.032979

Keli X, Mogha N, and Egan SE. 2010. Notch signaling in lung development and disease. Austin, TX: Landes Bioscience.

Kho AT, Bhattacharya S, Mecham BH, Hong J, Kohane IS, and Mariani TJ. 2009. Expression profiles of the mouse lung identify a molecular signature of time-to-birth. Am J Respir Cell Mol Biol 40:47-57. 10.1165/rcmb.2008-0048OC

Kho AT, Bhattacharya S, Tantisira KG, Carey VJ, Gaedigk R, Leeder JS, Kohane IS, Weiss ST, and Mariani TJ. 2010. Transcriptomic analysis of human lung development. Am J Respir Crit Care Med 181:54-63. 10.1164/rccm.200907-1063OC

Kho AT, Chhabra D, Sharma S, Qiu W, Carey VJ, Gaedigk R, Vyhlidal CA, Leeder JS, Tantisira KG, and Weiss ST. 2015. Age, Sexual Dimorphism and Disease Associations in the Developing Human Fetal Lung Transcriptome. Am J Respir Cell Mol Biol. 10.1165/rcmb.2015-0326OC

Kimura S, Hara Y, Pineau T, Fernandez-Salguero P, Fox CH, Ward JM, and Gonzalez FJ. 1996. The T/ebp null mouse: thyroid-specific enhancer-binding protein is essential for the organogenesis of the thyroid, lung, ventral forebrain, and pituitary. Genes Dev 10:60-69.

Kimura T, Kawabe H, Jiang C, Zhang W, Xiang YY, Lu C, Salter MW, Brose N, Lu WY, and Rotin D. 2011. Deletion of the ubiquitin ligase Nedd4L in lung epithelia causes cystic fibrosis-like disease. Proc Natl Acad Sci U S A 108:3216-3221. 10.1073/pnas.1010334108

Konigshoff M, Balsara N, Pfaff EM, Kramer M, Chrobak I, Seeger W, and Eickelberg O. 2008. Functional Wnt signaling is increased in idiopathic pulmonary fibrosis. PLoS One 3:e2142. 10.1371/journal.pone.0002142

Kramer CY. 1956. Extension of multiple range tests to group means with unequal number of replications. Biometrics 12:307-310.

Lemay AM, and Haston CK. 2005. Bleomycin-induced pulmonary fibrosis susceptibility genes in $\mathrm{AcB} / \mathrm{BcA}$ recombinant congenic mice. Physiol Genomics 23:54-61. 10.1152/physiolgenomics.00095.2005

Lu J, Izvolsky KI, Qian J, and Cardoso WV. 2005. Identification of FGF10 targets in the embryonic lung epithelium during bud morphogenesis. J Biol Chem 280:4834-4841. 10.1074/jbc.M410714200

Lu J, Qian J, Izvolsky KI, and Cardoso WV. 2004. Global analysis of genes differentially expressed in branching and non-branching regions of the mouse embryonic lung. Dev Biol 273:418-435. 10.1016/j.ydbio.2004.05.035

Mariani TJ, Reed JJ, and Shapiro SD. 2002. Expression profiling of the developing mouse lung: insights into the establishment of the extracellular matrix. Am J Respir Cell Mol Biol 26:541-548. 10.1165/ajrcmb.26.5.2001-00080c

Massaro D, and Massaro GD. 2008. Apoetm1Unc mice have impaired alveologenesis, low lung function, and rapid loss of lung function. Am J Physiol Lung Cell Mol Physiol 294:L991997. 10.1152/ajplung.00013.2008 
854

855

856

857

858

859

860

861

862

863

864

865

866

867

868

869

870

871

872

873

874

875

876

877

878

879

880

881

882

883

884

885

886

887

888

889

890

891

892

893

894

895

896

897

898

899

Metzger DE, Stahlman MT, and Shannon JM. 2008. Misexpression of ELF5 disrupts lung branching and inhibits epithelial differentiation. Dev Biol 320:149-160. 10.1016/j.ydbio.2008.04.038

Mi H, Muruganujan A, and Thomas PD. 2013. PANTHER in 2013: modeling the evolution of gene function, and other gene attributes, in the context of phylogenetic trees. Nucleic Acids Res 41:D377-386. 10.1093/nar/gks1118

Millien G, Beane J, Lenburg M, Tsao PN, Lu J, Spira A, and Ramirez MI. 2008. Characterization of the mid-foregut transcriptome identifies genes regulated during lung bud induction. Gene Expr Patterns 8:124-139. 10.1016/j.modgep.2007.09.003

Minoo P, Su G, Drum H, Bringas P, and Kimura S. 1999. Defects in tracheoesophageal and lung morphogenesis in Nkx2.1(-/-) mouse embryos. Dev Biol 209:60-71.

10.1006/dbio.1999.9234

Moore BB, Lawson WE, Oury TD, Sisson TH, Raghavendran K, and Hogaboam CM. 2013. Animal models of fibrotic lung disease. Am J Respir Cell Mol Biol 49:167-179. 10.1165/rcmb.2013-0094TR

Mund SI, Stampanoni M, and Schittny JC. 2008. Developmental alveolarization of the mouse lung. Dev Dyn 237:2108-2116. 10.1002/dvdy.21633

Pais RS, Moreno-Barriuso N, Hernandez-Porras I, Lopez IP, De Las Rivas J, and Pichel JG. 2013. Transcriptome analysis in prenatal IGF1-deficient mice identifies molecular pathways and target genes involved in distal lung differentiation. PLoS One 8:e83028. 10.1371/journal.pone.0083028

Pirooznia M, Nagarajan V, and Deng Y. 2007. GeneVenn - A web application for comparing gene lists using Venn diagrams. Bioinformation 1:420-422.

Rackley CR, and Stripp BR. 2012. Building and maintaining the epithelium of the lung. J Clin Invest 122:2724-2730. 10.1172/JCI60519

Rawlins EL, and Perl AK. 2012. The a"MAZE"ing world of lung-specific transgenic mice. Am J Respir Cell Mol Biol 46:269-282. 10.1165/rcmb.2011-0372PS

Reinhard C, Eder G, Fuchs H, Ziesenis A, Heyder J, and Schulz H. 2002. Inbred strain variation in lung function. Mamm Genome 13:429-437. 10.1007/s00335-002-3005-6

Rezvani M, Wilde J, Vitt P, Mailaparambil B, Grychtol R, Krueger M, and Heinzmann A. 2013. Association of a FGFR-4 gene polymorphism with bronchopulmonary dysplasia and neonatal respiratory distress. Dis Markers 35:633-640. 10.1155/2013/932356

Richardson JE, and Bult CJ. 2015. Visual annotation display (VLAD): a tool for finding functional themes in lists of genes. Mamm Genome. 10.1007/s00335-015-9570-2

Saeed AI, Sharov V, White J, Li J, Liang W, Bhagabati N, Braisted J, Klapa M, Currier T, Thiagarajan M, Sturn A, Snuffin M, Rezantsev A, Popov D, Ryltsov A, Kostukovich E, Borisovsky I, Liu Z, Vinsavich A, Trush V, and Quackenbush J. 2003. TM4: a free, open-source system for microarray data management and analysis. Biotechniques 34:374378.

Sandell LL, Sanderson BW, Moiseyev G, Johnson T, Mushegian A, Young K, Rey JP, Ma JX, Staehling-Hampton K, and Trainor PA. 2007. RDH10 is essential for synthesis of embryonic retinoic acid and is required for limb, craniofacial, and organ development. Genes Dev 21:1113-1124. 10.1101/gad.1533407

Sayers EW, Barrett T, Benson DA, Bolton E, Bryant SH, Canese K, Chetvernin V, Church DM, Dicuccio M, Federhen S, Feolo M, Fingerman IM, Geer LY, Helmberg W, Kapustin Y, Krasnov S, Landsman D, Lipman DJ, Lu Z, Madden TL, Madej T, Maglott DR, 
900

901

902

903

904

905

906

907

908

909

910

911

912

913

914

915

916

917

918

919

920

921

922

923

924

925

926

927

928

929

930

931

932

933

934

935

936

937

938

939

940

941

942

943

944

945

Marchler-Bauer A, Miller V, Karsch-Mizrachi I, Ostell J, Panchenko A, Phan L, Pruitt KD, Schuler GD, Sequeira E, Sherry ST, Shumway M, Sirotkin K, Slotta D, Souvorov A, Starchenko G, Tatusova TA, Wagner L, Wang Y, Wilbur WJ, Yaschenko E, and Ye J. 2012. Database resources of the National Center for Biotechnology Information. Nucleic Acids Res 40:D13-25. 10.1093/nar/gkr1184

Schittny JC, Mund SI, and Stampanoni M. 2008. Evidence and structural mechanism for late lung alveolarization. Am J Physiol Lung Cell Mol Physiol 294:L246-254.

10.1152/ajplung.00296.2007

Schraufnagel DE. 2010. Lung lymphatic anatomy and correlates. Pathophysiology 17:337-343. 10.1016/j.pathophys.2009.10.008

Schulz H, Johner C, Eder G, Ziesenis A, Reitmeier P, Heyder J, and Balling R. 2002. Respiratory mechanics in mice: strain and sex specific differences. Acta Physiol Scand 174:367-375. 10.1046/j.1365-201x.2002.00955.x

Shi W, Bellusci S, and Warburton D. 2007. Lung development and adult lung diseases. Chest 132:651-656. 10.1378/chest.06-2663

Shinagawa K, and Kojima M. 2003. Mouse model of airway remodeling: strain differences. Am J Respir Crit Care Med 168:959-967. 10.1164/rccm.200210-1188OC

Smith CL, and Eppig JT. 2012. The Mammalian Phenotype Ontology as a unifying standard for experimental and high-throughput phenotyping data. Mamm Genome 23:653-668. 10.1007/s00335-012-9421-3

Soutiere SE, Tankersley CG, and Mitzner W. 2004. Differences in alveolar size in inbred mouse strains. Respir Physiol Neurobiol 140:283-291. 10.1016/j.resp.2004.02.003

Taniwaki M, Daigo Y, Ishikawa N, Takano A, Tsunoda T, Yasui W, Inai K, Kohno N, and Nakamura Y. 2006. Gene expression profiles of small-cell lung cancers: molecular signatures of lung cancer. Int J Oncol 29:567-575.

Treutlein B, Brownfield DG, Wu AR, Neff NF, Mantalas GL, Espinoza FH, Desai TJ, Krasnow MA, and Quake SR. 2014. Reconstructing lineage hierarchies of the distal lung epithelium using single-cell RNA-seq. Nature 509:371-375. 10.1038/nature13173

Tusher VG, Tibshirani R, and Chu G. 2001. Significance analysis of microarrays applied to the ionizing radiation response. Proc Natl Acad Sci U S A 98:5116-5121. 10.1073/pnas.091062498

Usui H, Shibayama M, Ohbayashi N, Konishi M, Takada S, and Itoh N. 2004. Fgf18 is required for embryonic lung alveolar development. Biochem Biophys Res Commun 322:887-892. 10.1016/j.bbrc.2004.07.198

Walkin L, Herrick SE, Summers A, Brenchley PE, Hoff CM, Korstanje R, and Margetts PJ. 2013. The role of mouse strain differences in the susceptibility to fibrosis: a systematic review. Fibrogenesis Tissue Repair 6:18. 10.1186/1755-1536-6-18

Warburton D, Bellusci S, De Langhe S, Del Moral PM, Fleury V, Mailleux A, Tefft D, Unbekandt M, Wang K, and Shi W. 2005. Molecular mechanisms of early lung specification and branching morphogenesis. Pediatr Res 57:26R-37R. 10.1203/01.PDR.0000159570.01327.ED

Warburton D, El-Hashash A, Carraro G, Tiozzo C, Sala F, Rogers O, De Langhe S, Kemp PJ, Riccardi D, Torday J, Bellusci S, Shi W, Lubkin SR, and Jesudason E. 2010. Lung organogenesis. Curr Top Dev Biol 90:73-158. 10.1016/S0070-2153(10)90003-3

Warburton D, Schwarz M, Tefft D, Flores-Delgado G, Anderson KD, and Cardoso WV . 2000. The molecular basis of lung morphogenesis. Mech Dev 92:55-81. 
946 Weaver M, Dunn NR, and Hogan BL. 2000. Bmp4 and Fgf10 play opposing roles during lung 947 bud morphogenesis. Development 127:2695-2704.

948 Whitehead GS, Walker JK, Berman KG, Foster WM, and Schwartz DA. 2003. Allergen-induced

949 airway disease is mouse strain dependent. Am J Physiol Lung Cell Mol Physiol 285:L32-

950 42. 10.1152/ajplung.00390.2002

951 Wright JL, Cosio M, and Churg A. 2008. Animal models of chronic obstructive pulmonary

$952 \quad$ disease. Am J Physiol Lung Cell Mol Physiol 295:L1-15. 10.1152/ajplung.90200.2008

953 Xu Y, Wang Y, Besnard V, Ikegami M, Wert SE, Heffner C, Murray SA, Donahue LR, and

954

955 Whitsett JA. 2012. Transcriptional programs controlling perinatal lung maturation. PLoS One 7:e37046. 10.1371/journal.pone.0037046

Yalcin B, Adams DJ, Flint J, and Keane TM. 2012. Next-generation sequencing of experimental mouse strains. Mamm Genome 23:490-498. 10.1007/s00335-012-9402-6

Yates LL, and Dean CH. 2011. Planar polarity: A new player in both lung development and disease. Organogenesis 7:209-216. 10.4161/org.7.3.18462

Zhu Y, Richardson JE, Hale P, Baldarelli RM, Reed DJ, Recla JM, Sinclair R, Reddy TB, and Bult CJ. 2015. A unified gene catalog for the laboratory mouse reference genome. Mamm Genome 26:295-304. 10.1007/s00335-015-9571-1

963 
Figure 1 (on next page)

Comparison of mouse strains, time points, and platforms for genome wide expression profiling of murine lung development.

Shaded cells indicate time points included in published transcriptional profiles of mouse lung development. Images reflect the major anatomical changes at each embryonic stage of development. 


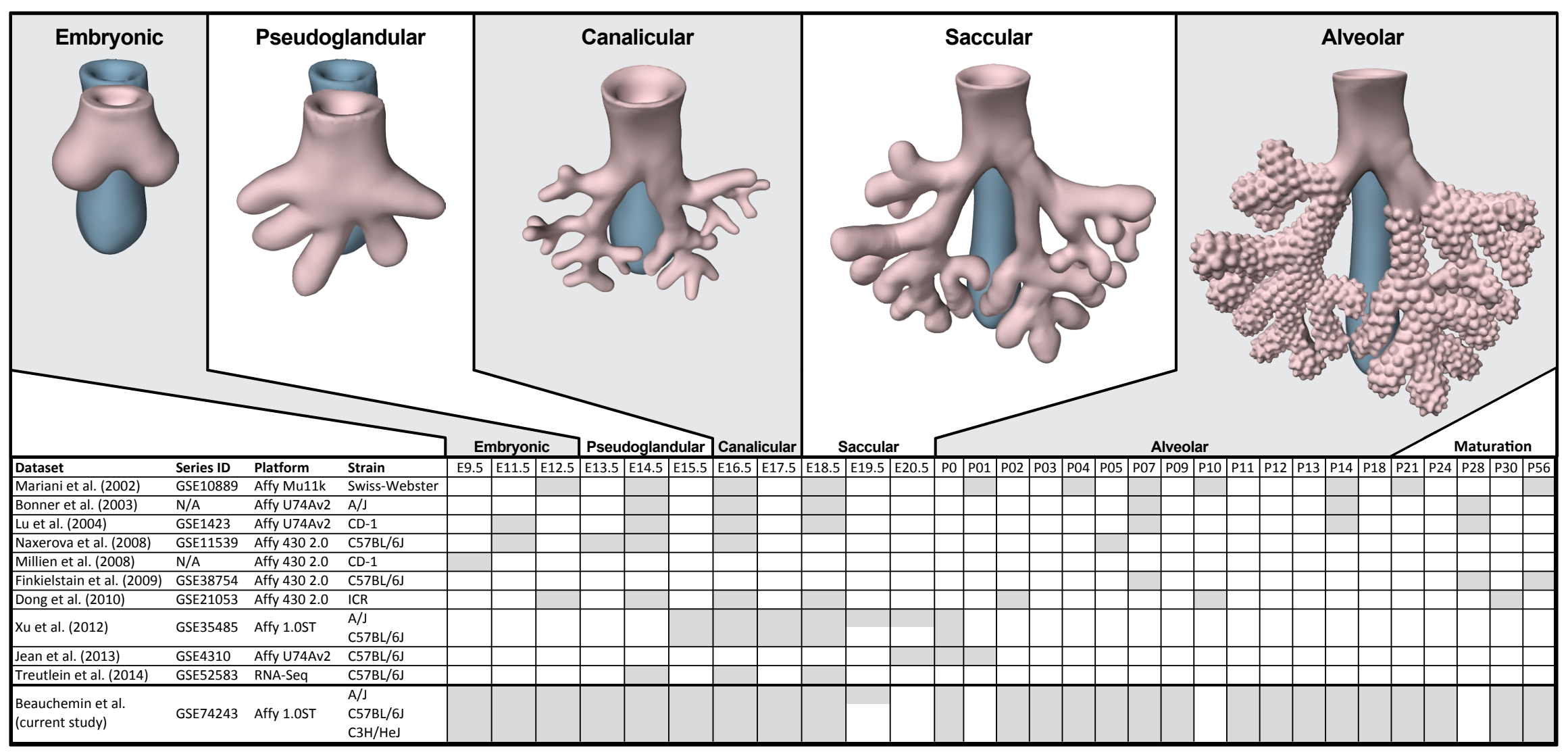


Figure 2 (on next page)

\section{Global patterns of sample variation across lung development.}

Plots of PCA scores (y-axis) for strain-independent principal components 1-3 along developmental time points and stages (X-axis). Time points: embryonic (E); postnatal (P). Stages: whole embryo (WE); embryonic (EMB); pseudoglandular (PSG); canalicular (CAN); saccular (SAC); alveolar (ALV1-4); mature lung (MAT). (A) PCA scores for principal components 1-3 (averaged across all three strains) across all developmental time points. (B) PCA scores for principal components 1-3 plotted for each mouse strain. 
Figure 3 (on next page)

\section{Regression modeling of gene expression as a function of strain and developmental stage.}

Results of the linear regression analysis performed on PCA scores from strain-dependent principal components (PC 4-10). (A) Plots of least square means (y-axis) showing stage effects. (B) Plots of least square means (y-axis) illustrating strain effects. (C) Annotation enrichment results for characteristic gene sets with positive or negative loadings on PCs 410. 


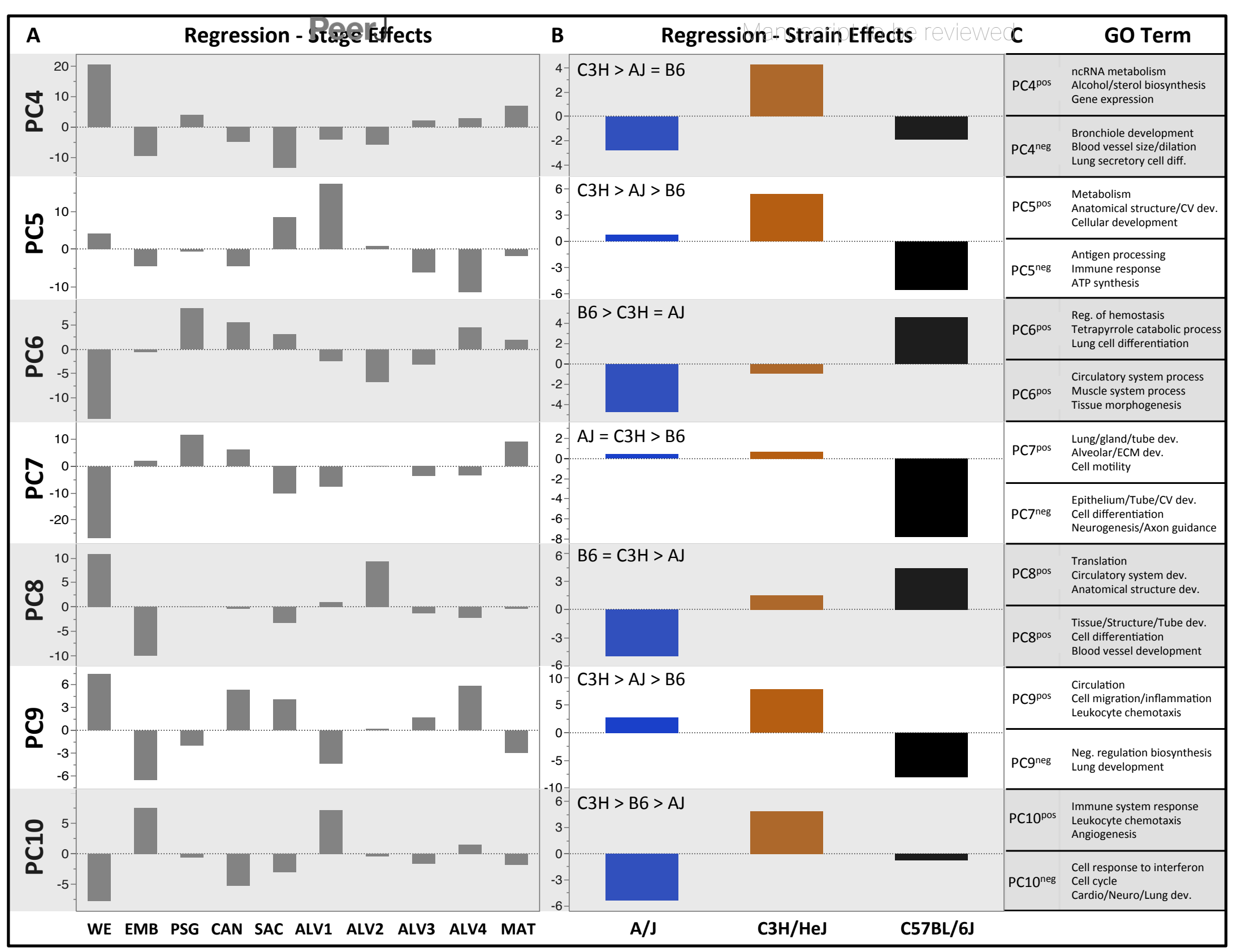




\section{Figure 4 (on next page)}

\section{Regression analysis supports nine molecular stages of lung development.}

Each set of colored bars represents the least square means of the stage effects for principal components 1-3. A summary of annotation enrichment categories are shown for the positive and negative characteristic gene sets from each component (complete results provided in Supplemental Information S6). 


\begin{tabular}{|c|c|c|c|c|c|c|c|c|c|c|}
\hline \multirow{2}{*}{$\begin{array}{l}\text { CANONICAL } \\
\text { STAGES } \\
\text { TIME POINTS }\end{array}$} & \multicolumn{2}{|r|}{ EMB } & PGSG & CAN & SAC & \multicolumn{4}{|c|}{ Manuscript to be reviowwed } & \multirow{2}{*}{$\frac{\text { MAT }}{\text { P21 P24 P30 P56 }}$} \\
\hline & E9.5 & $\begin{array}{ll}\text { E11.5 } & \text { E12.5 } \\
\end{array}$ & E13.5 E14.5 E15.5 & $\begin{array}{ll}\text { E16.5 } & \text { E17.5 } \\
\end{array}$ & $\begin{array}{ll}\text { E18.5 } & \text { E19.5 } \\
\end{array}$ & $\begin{array}{ll}\text { P0 } & \text { P2 } \\
\end{array}$ & $\begin{array}{lll}\text { P4 } & \text { P5 } & \text { P7 } \\
\end{array}$ & $\begin{array}{lll}\text { P9 } & \text { P11 } & \text { P12 } \\
\end{array}$ & P14 & \\
\hline $\begin{array}{l}\text { PROPOSED } \\
\text { STAGES }\end{array}$ & WE & EMB & PSG & CAN & SAC & ALV1 & ALV2 & ALV3 & ALV4 & MAT \\
\hline $\begin{array}{ll}\text { Cell cycle } \\
\stackrel{\text { DNA repair }}{\text { 넘 }} \\
\text { Gene express } \\
\text { Primary meta }\end{array}$ & $\begin{array}{l}\text { ion } \\
\text { iolism }\end{array}$ & & & & & & & & & \\
\hline $\begin{array}{ll}\text { Motility/local } \\
\text { ¿ै } \\
\text { Cell communi } \\
\text { Immune sys } p \\
\text { Signal transdu }\end{array}$ & $\begin{array}{l}\text { ization } \\
\text { cation } \\
\text { roc. } \\
\text { uction }\end{array}$ & & & & & & & & & \\
\hline $\begin{array}{ll}\text { Adhesion/Mi } \\
\text { ò } \\
\text { 음 Cpithelium de } \\
\text { Cardiovascula } \\
\text { ECM Organiza }\end{array}$ & $\begin{array}{l}\text { sration } \\
\text { iv. } \\
\text { ir dev. } \\
\text { tion }\end{array}$ & & & & & & & & & \\
\hline $\begin{array}{ll}\text { Neuron guida } \\
\text { ஸे Chemotaxis } \\
\text { Uั } \\
\text { Tube morpho } \\
\text { Anatomical d }\end{array}$ & & & & & & & & & & \\
\hline $\begin{array}{ll}\text { Peptide meta } \\
\text { 을 } \\
\text { Translation } \\
\text { Oxi-Reduc prc } \\
\text { Ribosome ass }\end{array}$ & $\begin{array}{l}\text { bolism } \\
\text { ocess } \\
\text { embly }\end{array}$ & & & & & & & & & \\
\hline $\begin{array}{ll} & \text { Tube/Tissue c } \\
& \text { Nervous sys. } \\
\text { ஸे } & \text { Cardiovascula } \\
\swarrow & \text { Cell Differenti }\end{array}$ & $\begin{array}{l}\text { lev. } \\
\text { dev. } \\
\text { i dev. } \\
\text { ation }\end{array}$ & & & & & & & & & \\
\hline
\end{tabular}


Figure $\mathbf{5}$ (on next page)

Comparison of mouse and human embryonic Developing Lung Characteristic Subtranscriptome (DLCS) gene sets.

Schematic of workflow for comparing embryonic DLCS gene sets from mouse and human.

Mouse genes were converted to human homolog gene symbols to facilitate comparison.

Results of annotation enrichment analysis for the unique and overlapping genes are listed.

Complete results available in Supplemental Information S9. 

Figure 6 (on next page)

Post-natal expression patterns of genes associated with alveolarization and angiogenesis.

Schematic of anti-correlated patterns of gene expression levels for genes associated with alveolarization and angiogenesis (solid line) versus negative regulation of angiogenesis (dotted line). The patterns illustrate functional genomics basis of the four stages of alveolar development proposed in this study. 


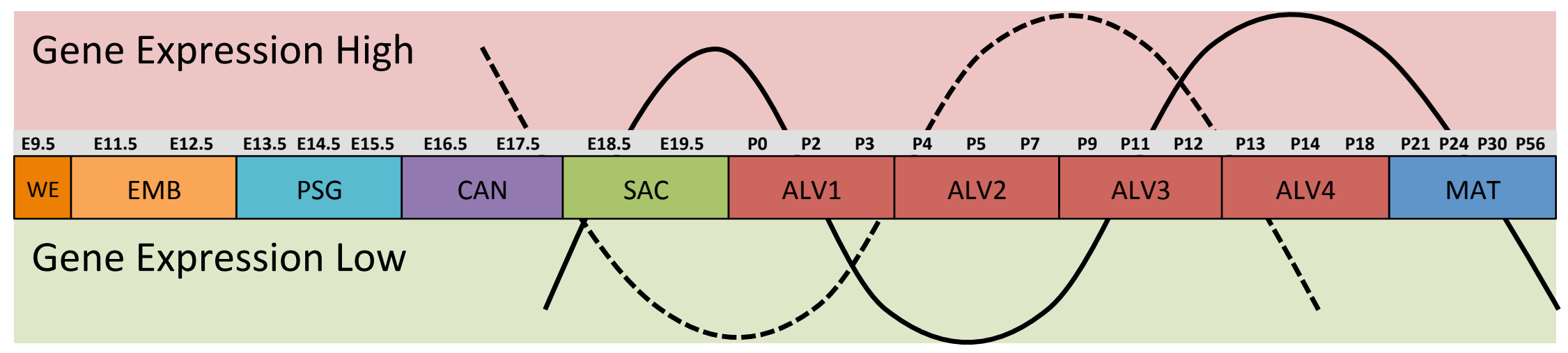

Alveolarization / Angiogenesis Negative Reg. of Angiogenesis 


\section{Table $\mathbf{1}$ (on next page)}

\section{Summary of analysis results for lung development transcriptional profiling in three inbred mouse strains.}

The cumulative variation in gene expression accounted for by the first 10 principal components is $80.9 \%$. Pearson Correlation results are from the pairwise correlation of PCA scores as a function of strain. Regression results show the significance levels of the effect of three variables (developmental stage, strain, and stage by strain interaction) for each Principal Component. Tukey HSD connecting letters diagram indicates relatedness of strains for each component. $*=p$-value $<0.01 ; * *=p$-value $<0.001 ; * * *=p$-value $<0.0001 . \dagger=$ significant effect after multiple testing correction (FDR $<0.1)$. The dataset used as input for the PCA and regression analyses is provided in Supplemental Data S2. 


\begin{tabular}{|c|c|c|c|c|c|c|c|}
\hline Component & Var. (\%) & \multicolumn{2}{|c|}{ Pearson Correlation $\left(\mathbf{R}^{2}\right)$} & \multicolumn{2}{|c|}{ Regression (Pval) } & \multicolumn{2}{|c|}{ Tukey HSD } \\
\hline PC1 & $\begin{array}{c}55.1 \\
(55.1)\end{array}$ & $\begin{array}{c}\mathrm{C} 57 \mathrm{BL} / 6 \mathrm{~J}-\mathrm{A} / \mathrm{J} \\
\mathrm{A} / \mathrm{J}-\mathrm{C} 3 \mathrm{H} / \mathrm{HeJ} \\
\mathrm{C} 57 \mathrm{BL} / 6 \mathrm{~J}-\mathrm{C} 3 \mathrm{H} / \mathrm{HeJ}\end{array}$ & $\begin{array}{l}.990 * * * \\
.993 * * * \\
.990 * * *\end{array}$ & $\begin{array}{c}\text { stage } \\
\text { strain } \\
\text { stage* } \text { strain }\end{array}$ & $\begin{array}{l}<.0001^{\dagger} \\
0.9131 \\
0.6566\end{array}$ & $\begin{array}{c}\mathrm{AJ} \\
\mathrm{B} 6 \\
\mathrm{C} 3 \mathrm{H}\end{array}$ & $\begin{array}{l}\mathrm{A} \\
\mathrm{A} \\
\mathrm{A}\end{array}$ \\
\hline $\mathrm{PC} 2$ & $\begin{array}{c}6.1 \\
(61.2)\end{array}$ & $\begin{array}{c}\mathrm{C} 57 \mathrm{BL} / 6 \mathrm{~J}-\mathrm{A} / \mathrm{J} \\
\mathrm{A} / \mathrm{J}-\mathrm{C} 3 \mathrm{H} / \mathrm{HeJ} \\
\mathrm{C} 57 \mathrm{BL} / 6 \mathrm{~J}-\mathrm{C} 3 \mathrm{H} / \mathrm{HeJ}\end{array}$ & $\begin{array}{l}.744 * * * \\
.839 * * * \\
.849 * * *\end{array}$ & $\begin{array}{c}\text { stage } \\
\text { strain } \\
\text { stage*strain }\end{array}$ & $\begin{array}{l}<.0001^{\dagger} \\
0.5970 \\
0.0038\end{array}$ & $\begin{array}{c}\mathrm{AJ} \\
\mathrm{B} 6 \\
\mathrm{C} 3 \mathrm{H}\end{array}$ & $\begin{array}{l}\mathrm{A} \\
\mathrm{A} \\
\mathrm{A}\end{array}$ \\
\hline $\mathrm{PC} 3$ & $\begin{array}{c}4.98 \\
(66.2)\end{array}$ & $\begin{array}{c}\mathrm{C} 57 \mathrm{BL} / 6 \mathrm{~J}-\mathrm{A} / \mathrm{J} \\
\mathrm{A} / \mathrm{J}-\mathrm{C} 3 \mathrm{H} / \mathrm{HeJ} \\
\mathrm{C} 57 \mathrm{BL} / 6 \mathrm{~J}-\mathrm{C} 3 \mathrm{H} / \mathrm{HeJ}\end{array}$ & $\begin{array}{l}.865 * * * \\
.739 * * * \\
.646 * * *\end{array}$ & $\begin{array}{c}\text { stage } \\
\text { strain } \\
\text { stage*strain }\end{array}$ & $\begin{array}{l}<.0001^{\dagger} \\
0.2229 \\
0.2090\end{array}$ & $\begin{array}{c}\mathrm{AJ} \\
\mathrm{B} 6 \\
\mathrm{C} 3 \mathrm{H}\end{array}$ & $\begin{array}{l}\mathrm{A} \\
\mathrm{A} \\
\mathrm{A}\end{array}$ \\
\hline PC4 & $\begin{array}{c}3.53 \\
(69.7)\end{array}$ & $\begin{array}{c}\mathrm{C} 57 \mathrm{BL} / 6 \mathrm{~J}-\mathrm{A} / \mathrm{J} \\
\mathrm{A} / \mathrm{J}-\mathrm{C} 3 \mathrm{H} / \mathrm{HeJ} \\
\mathrm{C} 57 \mathrm{BL} / 6 \mathrm{~J}-\mathrm{C} 3 \mathrm{H} / \mathrm{HeJ}\end{array}$ & $\begin{array}{l}.117 \\
.114 \\
.192\end{array}$ & $\begin{array}{c}\text { stage } \\
\text { strain } \\
\text { stage* }{ }^{*} \text { strain }\end{array}$ & $\begin{array}{l}<.0001^{\dagger} \\
0.0072 \\
0.0029\end{array}$ & $\begin{array}{c}\mathrm{AJ} \\
\mathrm{B} 6 \\
\mathrm{C} 3 \mathrm{H}\end{array}$ & $\begin{array}{l}\mathrm{B} \\
\mathrm{B} \\
\mathrm{A}\end{array}$ \\
\hline PC5 & $\begin{array}{c}2.83 \\
(72.5)\end{array}$ & $\begin{array}{c}\mathrm{C} 57 \mathrm{BL} / 6 \mathrm{~J}-\mathrm{A} / \mathrm{J} \\
\mathrm{A} / \mathrm{J}-\mathrm{C} 3 \mathrm{H} / \mathrm{HeJ} \\
\mathrm{C} 57 \mathrm{BL} / 6 \mathrm{~J}-\mathrm{C} 3 \mathrm{H} / \mathrm{HeJ}\end{array}$ & $\begin{array}{c}.379 * \\
.445 * * \\
.262\end{array}$ & $\begin{array}{c}\text { stage } \\
\text { strain } \\
\text { stage* strain }\end{array}$ & $\begin{array}{l}<.0001^{\dagger} \\
<.0001^{\dagger} \\
<.0001^{\dagger}\end{array}$ & $\begin{array}{c}\mathrm{AJ} \\
\mathrm{B} 6 \\
\mathrm{C} 3 \mathrm{H}\end{array}$ & $\begin{array}{l}\mathrm{B} \\
\mathrm{C} \\
\mathrm{A}\end{array}$ \\
\hline PC6 & $\begin{array}{c}2.27 \\
(74.8)\end{array}$ & $\begin{array}{c}\mathrm{C} 57 \mathrm{BL} / 6 \mathrm{~J}-\mathrm{A} / \mathrm{J} \\
\mathrm{A} / \mathrm{J}-\mathrm{C} 3 \mathrm{H} / \mathrm{HeJ} \\
\mathrm{C} 57 \mathrm{BL} / 6 \mathrm{~J}-\mathrm{C} 3 \mathrm{H} / \mathrm{HeJ}\end{array}$ & $\begin{array}{l}.130 \\
.231 \\
.214\end{array}$ & $\begin{array}{c}\text { stage } \\
\text { strain } \\
\text { stage* strain }\end{array}$ & $\begin{array}{l}<.0001^{\dagger} \\
<.0001^{\dagger} \\
0.0006^{\dagger}\end{array}$ & $\begin{array}{c}\mathrm{AJ} \\
\mathrm{B} 6 \\
\mathrm{C} 3 \mathrm{H}\end{array}$ & $\begin{array}{l}\mathrm{B} \\
\mathrm{A} \\
\mathrm{B}\end{array}$ \\
\hline PC7 & $\begin{array}{c}2.02 \\
(76.8)\end{array}$ & $\begin{array}{c}\mathrm{C} 57 \mathrm{BL} / 6 \mathrm{~J}-\mathrm{A} / \mathrm{J} \\
\mathrm{A} / \mathrm{J}-\mathrm{C} 3 \mathrm{H} / \mathrm{HeJ} \\
\mathrm{C} 57 \mathrm{BL} / 6 \mathrm{~J}-\mathrm{C} 3 \mathrm{H} / \mathrm{HeJ}\end{array}$ & $\begin{array}{l}.522 * * * \\
.561 * * * \\
.734 * * *\end{array}$ & $\begin{array}{c}\text { stage } \\
\text { strain } \\
\text { stage* strain }\end{array}$ & $\begin{array}{l}<.0001^{\dagger} \\
<.0001^{\dagger} \\
0.0385\end{array}$ & $\begin{array}{c}\mathrm{AJ} \\
\mathrm{B} 6 \\
\mathrm{C} 3 \mathrm{H}\end{array}$ & $\begin{array}{l}\text { A } \\
\text { B } \\
\text { A }\end{array}$ \\
\hline PC8 & $\begin{array}{c}1.55 \\
(78.4)\end{array}$ & $\begin{array}{c}\mathrm{C} 57 \mathrm{BL} / 6 \mathrm{~J}-\mathrm{A} / \mathrm{J} \\
\mathrm{A} / \mathrm{J}-\mathrm{C} 3 \mathrm{H} / \mathrm{HeJ} \\
\mathrm{C} 57 \mathrm{BL} / 6 \mathrm{~J}-\mathrm{C} 3 \mathrm{H} / \mathrm{HeJ}\end{array}$ & $\begin{array}{c}.286 \\
.469 * * * \\
.131\end{array}$ & $\begin{array}{c}\text { stage } \\
\text { strain } \\
\text { stage*strain }\end{array}$ & $\begin{array}{l}<.0001^{\dagger} \\
<.0001^{\dagger} \\
0.0437\end{array}$ & $\begin{array}{c}\mathrm{AJ} \\
\mathrm{B} 6 \\
\mathrm{C} 3 \mathrm{H}\end{array}$ & $\begin{array}{l}\mathrm{B} \\
\mathrm{A} \\
\mathrm{A}\end{array}$ \\
\hline PC9 & $\begin{array}{c}1.43 \\
(79.8)\end{array}$ & $\begin{array}{c}\mathrm{C} 57 \mathrm{BL} / 6 \mathrm{~J}-\mathrm{A} / \mathrm{J} \\
\mathrm{A} / \mathrm{J}-\mathrm{C} 3 \mathrm{H} / \mathrm{HeJ} \\
\mathrm{C} 57 \mathrm{BL} / 6 \mathrm{~J}-\mathrm{C} 3 \mathrm{H} / \mathrm{HeJ}\end{array}$ & $\begin{array}{c}.344 * \\
.479 * * * \\
.194\end{array}$ & $\begin{array}{c}\text { stage } \\
\text { strain } \\
\text { stage* strain }\end{array}$ & $\begin{array}{l}<.0001^{\dagger} \\
<.0001^{\dagger} \\
<.0001^{\dagger}\end{array}$ & $\begin{array}{c}\mathrm{AJ} \\
\mathrm{B} 6 \\
\mathrm{C} 3 \mathrm{H}\end{array}$ & $\begin{array}{l}\mathrm{B} \\
\mathrm{C} \\
\mathrm{A}\end{array}$ \\
\hline PC10 & $\begin{array}{c}1.08 \\
(80.9)\end{array}$ & $\begin{array}{c}\mathrm{C} 57 \mathrm{BL} / 6 \mathrm{~J}-\mathrm{A} / \mathrm{J} \\
\mathrm{A} / \mathrm{J}-\mathrm{C} 3 \mathrm{H} / \mathrm{HeJ} \\
\mathrm{C} 57 \mathrm{BL} / 6 \mathrm{~J}-\mathrm{C} 3 \mathrm{H} / \mathrm{HeJ}\end{array}$ & $\begin{array}{c}.320 \\
.386^{* *} \\
.181\end{array}$ & $\begin{array}{c}\text { stage } \\
\text { strain } \\
\text { stage* strain }\end{array}$ & $\begin{array}{l}<.0001^{\dagger} \\
<.0001^{\dagger} \\
<.0001^{\dagger}\end{array}$ & $\begin{array}{c}\mathrm{AJ} \\
\mathrm{B} 6 \\
\mathrm{C} 3 \mathrm{H}\end{array}$ & $\begin{array}{l}\mathrm{C} \\
\mathrm{B} \\
\mathrm{A}\end{array}$ \\
\hline
\end{tabular}

1 


\section{Table 2 (on next page)}

\section{Summary of strain-dependent expression patterns for lung development transcriptional profiling in three inbred mouse strains.}

Four classes of strain-dependent gene expression account for the strain effects observed on PC 4-10. The percentage of genes in each of the four classes is based on total number of genes with significant strain-differences by Tukey HSD $(Q<0.05)$. The patterns within classes reflect the expression levels of genes in the outlier strain relative to the indistinguishable strains. The percentages of genes for each pattern are based on the total of genes in the parent class. $(\mathrm{AJ}=\mathrm{A} / \mathrm{J} ; \mathrm{C} 3 \mathrm{H}=\mathrm{C} 3 \mathrm{H} / \mathrm{He}) ; \mathrm{B} 6=\mathrm{C} 57 \mathrm{BL} / 6 \mathrm{~J})$. 


\begin{tabular}{|l|cc|}
\hline CLASSES $(4)$ & \multicolumn{2}{|c|}{ PATTERNS } \\
\hline $\mathbf{C 3 H} \neq \mathbf{A J} \approx \mathbf{B 6}$ & $\mathrm{C} 3 \mathrm{H}>\mathrm{AJ} \approx \mathrm{B} 6$ & $\mathrm{C} 3 \mathrm{H}<\mathrm{AJ} \approx \mathrm{B} 6$ \\
223 genes $(28.6 \%)$ & 89 genes $(39.9 \%)$ & 134 genes $(60.1 \%)$ \\
$\mathbf{B} 6 \neq \mathbf{A J} \approx \mathbf{C 3 H}$ & $\mathrm{B} 6>\mathrm{C} 3 \mathrm{H} \approx \mathrm{AJ}$ & $\mathrm{B} 6<\mathrm{C} 3 \mathrm{H} \approx \mathrm{AJ}$ \\
349 genes $(44.7 \%)$ & 142 genes $(40.7 \%)$ & 207 genes $(59.3 \%)$ \\
$\mathbf{A J} \neq \mathbf{B 6} \approx \mathbf{C 3 H}$ & $\mathrm{AJ}>\mathrm{B} 6 \approx \mathrm{C} 3 \mathrm{H}$ & $\mathrm{AJ}<\mathrm{B} 6 \approx \mathrm{C} 3 \mathrm{H}$ \\
152 genes $(19.5 \%)$ & 85 genes $(55.9 \%)$ & 67 genes $(44.1 \%)$ \\
$\mathbf{C} 3 \mathbf{H} \neq \mathbf{A J} \neq \mathbf{B 6}$ & & \\
57 genes $(7.3 \%)$ & & \\
\hline
\end{tabular}

1 


\section{Table 3(on next page)}

Summary of Reactome pathway enrichment results for the $\mathbf{7 7 1}$ genes represented in both mouse and human embryonic developing lung characteristic subtranscriptomes.

Entities refer to proteins, molecules, sequences, and other physical complexes associated with a given pathway in Reactome database; entities found are those associated with input gene sets and total entities refers to all entities in a given pathway. FDR represents multiple testing corrected $p$-values for enrichment. 


\begin{tabular}{|c|c|c|c|c|}
\hline & $\begin{array}{l}\text { Entities } \\
\text { Found: }\end{array}$ & $\begin{array}{l}\text { Entities } \\
\text { Total: }\end{array}$ & $\begin{array}{l}\text { Percent } \\
\text { Total: }\end{array}$ & FDR: \\
\hline Cell Cycle: & 92 & 608 & $15.1 \%$ & $8.97 \times 10^{-14}$ \\
\hline Cell Cycle Checkpoints & 22 & 169 & $13.0 \%$ & $1.80 \times 10^{-2}$ \\
\hline ATR Response to Replication Stress & 8 & 39 & $20.5 \%$ & $4.77 \times 10^{-2}$ \\
\hline Mitotic G1-G1/S Phases & 21 & 139 & $15.1 \%$ & $4.46 \times 10^{-3}$ \\
\hline Pre-replicative Complex Activation & 8 & 33 & $24.2 \%$ & $2.76 \times 10^{-2}$ \\
\hline Mitotic G2-G2/M Phases & 23 & 141 & $16.3 \%$ & $7.50 \times 10^{-4}$ \\
\hline Polo-like Kinase-mediated Events & 9 & 23 & $39.1 \%$ & $6.70 \times 10^{-4}$ \\
\hline S Phase & 16 & 140 & $11.4 \%$ & $9.08 \times 10^{-2}$ \\
\hline M Phase & 51 & 316 & $16.1 \%$ & $2.84 \times 10^{-8}$ \\
\hline Resolution Chromatid Cohesion & 27 & 128 & $21.1 \%$ & $1.83 \times 10^{-6}$ \\
\hline Metabolism: & 135 & 3163 & $4.3 \%$ & $1.00 \times 10^{1}$ \\
\hline Erythrocyte Gas Exchange & 4 & 16 & $25.0 \%$ & $1.40 \times 10^{-1}$ \\
\hline Surfactant Metabolism & 7 & 52 & $13.5 \%$ & $1.96 \times 10^{-1}$ \\
\hline Immune System: & 132 & 1841 & $7.2 \%$ & $6.69 \times 10^{-2}$ \\
\hline Adaptive Immune System & 75 & 1002 & $7.5 \%$ & $1.18 \times 10^{-1}$ \\
\hline TCR Signaling & 25 & 145 & $17.2 \%$ & $1.63 \times 10^{-4}$ \\
\hline MHC-II Antigen Presentation & 30 & 141 & $21.3 \%$ & $3.20 \times 10^{-7}$ \\
\hline Costimulation by CD28 family & 24 & 96 & $25.0 \%$ & $5.42 \times 10^{-7}$ \\
\hline PD-1 Signaling & 17 & 45 & $37.8 \%$ & $3.20 \times 10^{-7}$ \\
\hline Cytokine Signaling in Immunity & 68 & 678 & $10.0 \%$ & $5.66 \times 10^{-4}$ \\
\hline Interferon Signaling & 35 & 289 & $12.1 \%$ & $2.43 \times 10^{-3}$ \\
\hline Interferon gamma signaling & 21 & 138 & $15.2 \%$ & $3.77 \times 10^{-2}$ \\
\hline Antiviral mechanism IFN-stimulated & 13 & 83 & $15.7 \%$ & $3.60 \times 10^{-2}$ \\
\hline Interleukin Signaling & 31 & 358 & $8.7 \%$ & $1.56 \times 10^{-1}$ \\
\hline DAP12 Signaling & 33 & 364 & $9.1 \%$ & $9.02 \times 10^{-2}$ \\
\hline Developmental Biology: & 86 & 904 & $9.5 \%$ & $8.68 \times 10^{-6}$ \\
\hline Axon Guidance & 66 & 568 & $11.6 \%$ & $8.68 \times 10^{-6}$ \\
\hline L1CAM Interactions & 16 & 124 & $12.9 \%$ & $5.66 \times 10^{-2}$ \\
\hline NCAM Signaling (neurite out-growth) & 29 & 298 & $9.7 \%$ & $6.69 \times 10^{-2}$ \\
\hline Semaphorin Interactions & 11 & 73 & $15.1 \%$ & $6.69 \times 10^{-2}$ \\
\hline Signaling by Robo Receptor & 8 & 38 & $21.1 \%$ & $4.44 \times 10^{-2}$ \\
\hline Signal Transduction: & 211 & 2710 & $7.79 \%$ & $3.42 \times 10^{-1}$ \\
\hline PIP3 Activates AKT Signaling & 15 & 121 & $12.4 \%$ & $6.69 \times 10^{-2}$ \\
\hline IRS-mediated Signaling & 28 & 306 & $9.2 \%$ & $1.21 \times 10^{-1}$ \\
\hline SCF-KIT Signaling & 34 & 339 & $10.0 \%$ & $3.94 \times 10^{-2}$ \\
\hline EGFR Signaling & 38 & 376 & $10.1 \%$ & $2.76 \times 10^{-2}$ \\
\hline FGFR Signaling & 33 & 356 & $9.3 \%$ & $7.44 \times 10^{-2}$ \\
\hline PDGF Signaling & 38 & 392 & $9.7 \%$ & $3.88 \times 10^{-2}$ \\
\hline ERBB2 Signaling & 33 & 360 & $9.2 \%$ & $8.04 \times 10^{-2}$ \\
\hline ERBB4 Signaling & 34 & 345 & $9.9 \%$ & $4.77 \times 10^{-2}$ \\
\hline Rho GTPase Signaling & 64 & 418 & $15.3 \%$ & $1.52 \times 10^{-9}$ \\
\hline NGF Signaling & 43 & 478 & $9.0 \%$ & $6.29 \times 10^{-2}$ \\
\hline Wnt Signaling & 35 & 326 & $10.7 \%$ & $1.74 \times 10^{-2}$ \\
\hline IGF1R Signaling & 29 & 311 & $9.3 \%$ & $9.40 \times 10^{-2}$ \\
\hline
\end{tabular}

1 